Portland State University

PDXScholar

Winter 4-8-2013

\title{
The Production of Organic Nitrates in Portland Oregon and the Columbia River Gorge
}

Holly Ann Neill

Portland State University

Follow this and additional works at: https://pdxscholar.library.pdx.edu/open_access_etds

Part of the Atmospheric Sciences Commons, and the Environmental Sciences Commons Let us know how access to this document benefits you.

\section{Recommended Citation}

Neill, Holly Ann, "The Production of Organic Nitrates in Portland Oregon and the Columbia River Gorge" (2013). Dissertations and Theses. Paper 681.

https://doi.org/10.15760/etd.681

This Thesis is brought to you for free and open access. It has been accepted for inclusion in Dissertations and Theses by an authorized administrator of PDXScholar. Please contact us if we can make this document more accessible: pdxscholar@pdx.edu. 
The Production of Organic Nitrates in Portland, Oregon and the Columbia River Gorge

by

Holly Ann Neill

A thesis submitted in partial fulfillment of the

requirements for the degree of

Thesis Committee:

Linda A. George, Chair

Juliane L. Fry

Kelley Barsanti

Portland State University

2013 


\section{Abstract}

This work studied the production of aerosol-phase organic nitrates in both Portland and the Columbia River Gorge (CRG). Ozone and $\mathrm{NO}_{\mathrm{x}}$ species were investigated for correlation with organic nitrate aerosol, as they function as precursors to the production of organic nitrates. These ambient gas-phase measurements were collected in the same locations as high-volume (Hi-Vol) filters samples, in an urban and rural gorge setting to investigate correlations at the origin of the pollution plume and downwind. A novel Soxhlet extraction method for Hi-Vol filters was developed based on literature and EPA standard methods. Analysis for nitrate production was done by segregating data based on times when the wind blew out of Portland and down the CRG versus times when flow was not westerly. Filters were then compared to ambient gas-phase measurements and derived $\mathrm{NO}_{3}$ radical production rates to look for trends. Wind direction had a strong influence on the concentrations of precursor molecules in the CRG. On days with a westerly wind direction into the gorge, concentrations of the measure aerosol organic nitrates were similar at both sides. This suggests some contribution of a broader regional production of organic nitrates. There was some correlation between the production rate of $\mathrm{NO}_{3}$ radicals and the measured organic nitrate aerosol, suggesting a role for $\mathrm{NO}_{3}+\mathrm{VOC}$ production of organic nitrates that later partition to the aerosol phase. This information will better illuminate the fate of nitrogen downwind of pollution sources. The information will also help to create a better understanding of the way 
topography and meteorological conditions can influence the flow of pollution.

Understanding the downwind oxidative chemistry that happens in the CRG would better support both pollution prevention and mitigation efforts. 


\section{Dedication}

I would like to dedicate this thesis to my husband Erik Neill whose invaluable support during sampling and data analysis helped to produce a much greater thesis than I could have done on my own. 


\section{Acknowledgments}

I would like to express thanks to my thesis committee, Linda George, Julie Fry, and Kelley Barsanti for their incredible support and guidance over the past few years. I want to especially thank Julie Fry for providing lab space and equipment. A lot of thanks goes to Linda George for her support. I would also like to thank Bob Jones and Ron Cunningham at the Oregon Department of Environmental Quality for help with equipment set-up and providing technical expertise. I would also like to show gratitude to Carl Henesy at Washington State Parks for allowing us to experiment at Beacon Rock State Park. I am also grateful for the support of my lab mates, they helped quite a bit. Lots of love goes out to my great family and the support they gave during the last three years while I worked on this project. Extra special thanks also go out to my husband Erik Neill for his creation of the sampling program that was used to run the sampling equipment and also for his help with using python as an analysis tool. 


\section{Table of Contents}

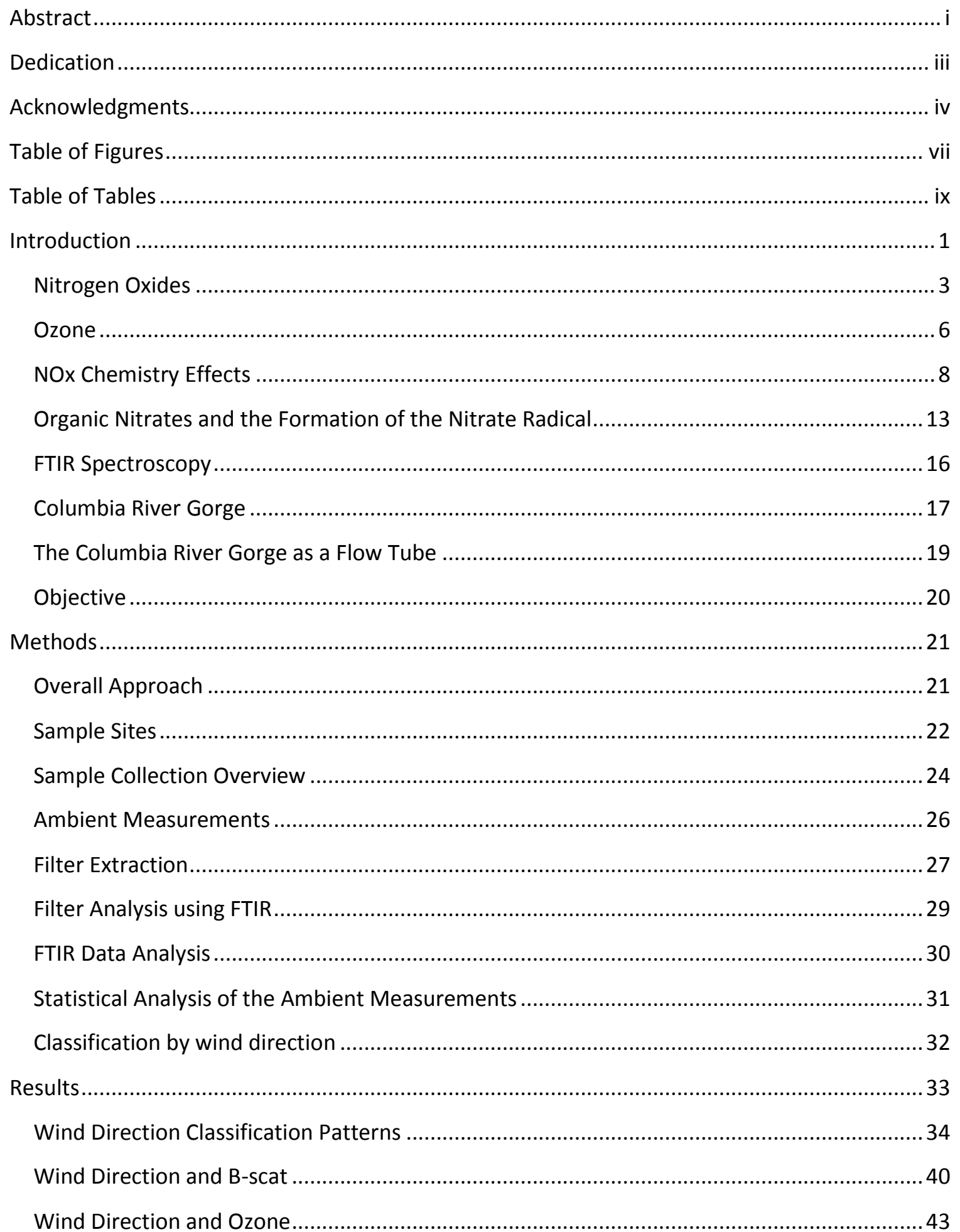




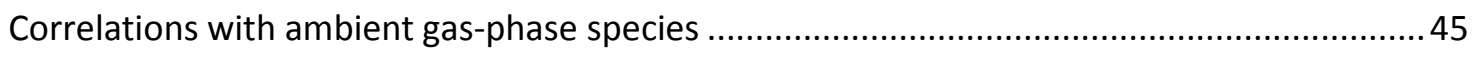

Relationships between Filter Organic Nitrates and Ambient Data........................................ 47

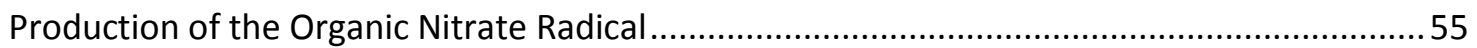

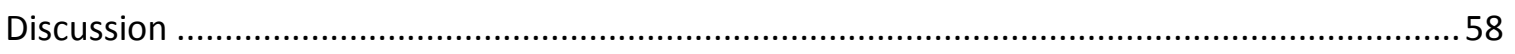

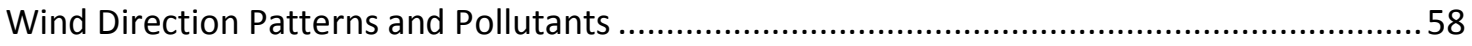

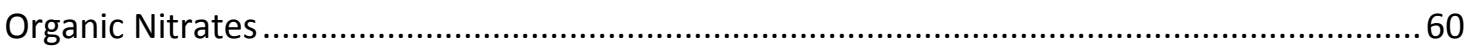

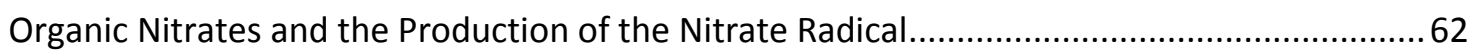

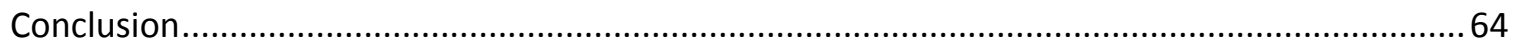

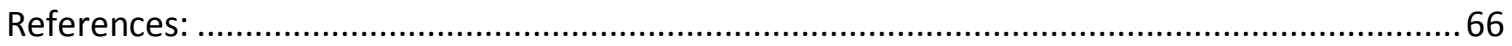




\section{Table of Figures}

Figure 1 Map of Sampling Sites.

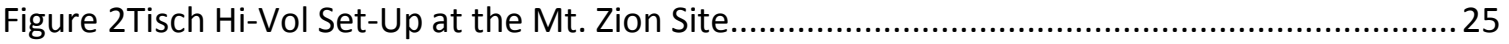

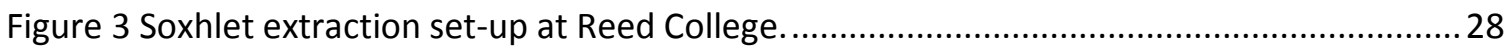

Figure 4 An example of spectra peak integration by hand......................................................... 30

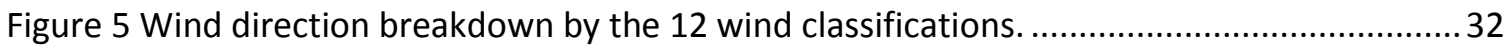

Figure 6 Wind direction classifications in Portland Oregon during the summers of 2010 and 2011.

Figure 7 Wind direction classifications in Portland Oregon during the summers of 2010 and 2011

Figure 8 Wind direction classifications in Mt. Zion Washington during the summer of 2010 and 2011.

Figure 9 The wind direction at Mt. Zion is predominantly west when the wind direction is NNW in Portland.

Figure 10: Average levels of B-scat by wind direction at Mt. Zion Washington over both sampling summers. Error bars indicate standard error. 40

Figure 11 Average Daily B-scat by wind classification at the Portland Oregon site. Error bars indicate standard error.

Figure 12 Average daily b-scat by wind classifications at the Canby site. Error bars indicate standard error.

Figure 13 Average daily ozone concentrations by wind classifications at the Mt. Zion site. Error bars indicate standard error.

Figure 14 Average daily Ozone at the Portland Oregon site by wind classifications. Error bars indicate standard error.

Figure 15 Ozone Concentrations by Wind Direction at Canby Oregon. Error bars indicate standard error.

Figure 16 The correlation between Ozone concentrations in Portland and Mt. Zion and wind direction in the Gorge

Figure 17 Wind Roses on September 12th, 2011. The blue wind rose represents wind at Mt.

Zion, the Red at Portland

Figure 18 Spectra showing the September 12th filter. The Reed filter is shown in red, the Mt. Zion filter is shown in blue. 48

Figure 19 Relationship between observed organic nitrate and filter mass..................................48

Figure 20 Correlation between both observed organic nitrate and temperature.

Figure 21 Relationship between absolute humidity and observed organic nitrates in the field. . 50 Figure 22 Relationship between the day of sampling ozone and the observed organic nitrate in the field.

Figure 23 The relationship between day of NO2 and organic nitrates in the field has very little significance. 
Figure 24 Ratios of observed organic nitrate concentration of $\mathrm{NO}_{3}$ at Reed and Mt.Zion on westerly and non westerly days.

Figure 25 This chart is showing the correlation between observed organic nitrate levels and general wind direction.

Figure 26 Relationship between observed aerosol organic nitrate and production of the nitrate radical, calculated from observed ambient $\mathrm{NO}_{2}$ and $\mathrm{O}_{3}$ concentrations (see text). 55

Figure 27: Levels of organic nitrate are much more strongly correlated with NO3 production in Portland. Diamonds indicate very hot days (mean temperature $>30^{\circ} \mathrm{C}$ ) 


\section{Table of Tables}

Table 1 Dates for the summer of 2010 and 2011 sampling periods........................................... 21

Table 2 Specific Site locations, including latitude and longitude

Table 3 Site Descriptions illustrating the area around the sampling site.

Table 4 Specific site instrumentation for each equipment location.

Table 5 The number of days in each month in which ambient B-Scat data was available 38

Table 6 Numerical Distribution of Ozone by wind direction at the Mt. Zion site. 


\section{Introduction}

Air pollution plays an important role in our interaction with the natural ecosystem. Understanding how air pollution affects the air we breathe can facilitate better pollution controls and reductions. Early air quality studies looked at the formation of tropospheric organic species in the gas phase and identified several organic molecules like alkenes and hydrocarbons as an area of concern (Atkinson 1990).

Transportation plays a large role in our ability to grow as a society, but it is also a significant source of air pollution (Colvile 2001). Nitrogen deposition has increased over the western United States since 1985 due to increases in urbanization, increased transportation, and increases in the number of confined animal feeding operations (Fenn 2003). Pollutants like nitrogen oxides $\left(\mathrm{NO}_{\mathrm{x}}\right)$ have a significant deposition effect and can be an important precursor molecule for other secondary air pollutants (Gruber 2008). A secondary pollutant refers to the fact that it is created in the air as a product of an atmospheric reaction from primary pollutants, often times from transportation process. An aerosol is a particulate that is suspended in gas.

Many governing bodies like the United States Environmental Protection Agency have highlighted the importance of regulating air pollution in an effort to reduce the impact that air pollution has on the environment (Cooper 2000). The importance of regulation can be seen in the example of the 2008 Olympic Games in Beijing China, where transportation control measures greatly reduced pollution emissions into the air, 
and at the same time reduced human exposure (Zhou 2010). Understanding air pollution plays a large role in prevention. Many exposure studies have shown a strong link between high concentrations of particulate matter and volatile organic carbons and high incidence rates asthma and death. (Weisel 2002).

Previous studies have characterized sources of pollution in the Gorge (Green 2007), and also the effect that pollution has on visibility (Green 2008). Recent studies have focused on carbon dioxde $\left(\mathrm{CO}_{2}\right)$ (Rice 2011) or on ozone $\left(\mathrm{O}_{s}\right)$ distribution in western Washington (Cooper 2000). Other studies using lichen as indicators of pollution have found higher levels of nitrogen near the western end of the Columbia River Gorge (CRG) (Fenn 2007). However, these studies have not shown specific instances of the CRG acting as a flow tube, nor have they investigated the atmospheric chemistry in the plume as it ages.

This study looks at the effect of air pollution from the Portland Metropolitan area on nearby National Scenic Area, the CRG. Understanding how transportation related pollutants and their secondary products are meteorologically transported will help to create better regulations to protect a national area. This study will specifically look at the summer urban outflow, and on the atmospheric chemistry that is taking place during transport. This study will consider specific days in the summers of 2010 and 2011 and determine if flow tube behavior can be observed in the CRG and the effect that the pollution outflow has on production of aerosol organic nitrates. 


\section{Nitrogen Oxides}

Nitrogen has several very important roles in the global ecosystem, including a large role in controlling primary production in the biosphere and is a limiting factor for plants grown for food by humans (Gruber 2008; Zhou 2010). It has been hypothesized that since the 1990's, more than 160 teragrams of Nitrogen have been added to the atmosphere by anthropogenic sources like fossil fuel combustion or food production (Gruber 2008). With the expansion of the global population, it can be expected that even more nitrogen will be added to the environment as more people drive cars, and food production is increased. This increased nitrogen comes in the form of many pollutants and poses a global problem for air, water, and soil quality.

Air pollution has been recognized as a significant problem throughout history as evidenced by writings from famous philosophers like Moses Maimonides from the $11^{\text {th }}$ century to King Edward I, who passed a law banning coal burning while parliament was in session (Gaffney 2009). Recent history air pollution problems like the killer smogs in Pennsylvania and England in the 1940's and 1950's lead to a change in the way that air pollution was managed. In 1970 in the United States, the passing of the Clean Air Act amendments provided a set of regulations to control air emissions from area, stationary, and mobile sources and established the National Ambient Air Quality Act (Vallero 2008). This legislative act founded the groundwork for improving air quality and 
livability for communities across the nation. One of the primary pollutants that the EPA set out to regulate were nitrogen oxides, or $\mathrm{NO}_{x}$.

$\mathrm{NO}_{x}$ refers to nitrogen oxides and is sum of $\mathrm{NO}_{2}$ and $\mathrm{NO}$. These reactive nitrogen compounds are found in the products of fossil fuel combustion (Colvile 2001; Charron 2003). In the atmosphere at ambient temperatures, nitrogen and oxygen do not react with each other, however at high temperatures, like found during combustion; they react to form nitrogen dioxide and nitric oxide. A total of $18,017,423$ tons of $\mathrm{NO}_{x}$ were released in 2005 according to the EPA. When looking at the anthropogenic sources of $\mathrm{NO}_{x}, 21 \%$ of the emissions or $3,783,659$ tons are generated by power plants for electricity generation. $36 \%$ or $6,491,821$ tons of emissions were generated by on road vehicles in 2008 (Agency 2010). Nitrogen oxides are also formed naturally by lightning and soil emissions.

During the daytime, the concentrations of $\mathrm{NO}$ and $\mathrm{NO}_{2}$ are controlled by combustion with their ratio determined by $\mathrm{O}_{3}$. The chemistry is controlled by the following basic reactions:

$$
\begin{gathered}
\mathrm{NO}+\mathrm{O}_{3} \rightarrow \mathrm{NO}_{2} \\
\mathrm{NO}_{2}+\mathrm{hv} \rightarrow \mathrm{NO}+\mathrm{O} .
\end{gathered}
$$

This reaction influences the production of ozone through:

$$
\mathrm{O}+\mathrm{O}_{2}+\mathrm{M} \rightarrow \mathrm{O}_{3}+\mathrm{M}
$$


As more $\mathrm{O}$ is formed, this creates more $\mathrm{O}_{3}$.

$\mathrm{NO}_{x}$ has a wide variety of impacts on the atmosphere. These impacts pose serious health and environmental hazards. For example, nitrogen oxide compounds play a significant role in ozone production, secondary organic aerosol formation, and the formation of $\mathrm{NO}_{3}$. In the presence of $\mathrm{VOC}^{\prime} \mathrm{s}$ and sunlight, $\mathrm{NO}_{x}$ participates in the creation of photochemical smog. $\mathrm{O}_{3}$ and particulate matter are also components of smog and have serious health consequences (Migliore 2009). $\mathrm{NO}_{\mathrm{x}}$ is also eventually broken down in the atmosphere to create $\mathrm{HNO}_{3}$ by the following pathway:

$$
\begin{aligned}
& 2 \mathrm{NO}_{2}+\mathrm{H}_{2} \mathrm{O} \rightarrow \mathrm{HNO}_{2}+\mathrm{HNO}_{3} \\
& 3 \mathrm{HNO}_{2} \rightarrow \mathrm{HNO}_{3}+2 \mathrm{NO}+\mathrm{H}_{2} \mathrm{O} .
\end{aligned}
$$

This creates acid rain, which has a significant effect on biological systems.

Peroxyacyl nitrates, or PAN's, are related nitrogen oxides as a product of the breakdown of hydrocarbons and $\mathrm{NO}_{2}$. PAN's are created in photochemical smog as Ozone breaks down the VOC's, which then react with $\mathrm{NO}_{2}$ to create a new compound which is a powerful eye irritant. PAN's are a compound with an R-group from a VOC attached to the terminal carbon of a carbonyl bond reacted with a $\mathrm{NO}_{2}$ molecule. This type of nitrogen oxide is important chemically for the environment because it dissolves more easily in water than in ozone, so it will break down slowly in the atmosphere 
allowing it to be more easily transported further away where it can be broken down and the $\mathrm{NO}_{2}$ molecule can be used again in the formation of ozone.

\section{Ozone}

A significant reason that nitrogen oxides are regulated is due to the creation of ozone that results from $\mathrm{NO}_{x}$ reacting in the atmosphere. During the day, ozone is formed in the troposphere. Peroxy radicals react with $\mathrm{NO}$ to form $\mathrm{NO}_{2} . \mathrm{NO}_{2}$ then reacts in the presence of sunlight to form NO. This frees an oxygen to react with molecular oxygen in the atmosphere to form ozone, or $\mathrm{O}_{3}$. Troposphere ozone has a significant effect on human health and plant productivity (Leisner 2012). Known as a secondary air pollutant due to its formation from primary pollutants, it can be present in high concentrations a significant distance from industrial and metropolitan regions due to the way it is formed (Berman 2012). Ozone reduces plant productivity by forming a reactive oxygen species in the plant and decreasing photosynthesis which in turn reduces plant growth and biomass accumulation (Anisworth 2012). Ozone in the troposphere decreases both forest productivity and crop yields which have a significant effect on local and global economies (Leisner 2012).

It has been established that ozone causes health effects for the human respiratory system, specifically as the ozone is highly reactive with tissues. Exposure to elevated concentrations of ozone can lead to increased hospital admissions for pneumonia, asthma, and other respiratory disease (Ebi 2008). In China, higher mortality 
rates are closely correlated with increases in Ozone concentration (Tao 2012). Ozone concentrations can also have a deleterious effect on indoor air quality, where it can have the same health effects as Ozone concentrations outside (Chen 2012).Chemically, Ozone also can cause serious health effects by the breakdown of VOC's in the atmosphere. Ozone is also a greenhouse gas that absorbs infrared (IR) energy which effects the heating and cooling of the planet. There are concerns that with the projected climate change, this would lead to increased levels of ozone and in turn increased human health impacts, specifically as a pulmonary irritant (Ebi 2008). Ozone is estimated to cause the deaths of 700,000 people and cause global economics losses of \$14 to \$26 billion dollars (Anisworth 2012).

As part of the Clean Air Act, the United States Environmental protection Agency (EPA) is required to set a standard for ozone that protects public health and welfare (Buller-McDonald 2011). Understanding the background levels of zone for health hazard quantification and rule-making has proven a significant challenge due to the way that ozone can be formed at a significant distance from its source. Current increases in ozone concentrations pose significant future risk for both human and plant health (Buller-McDonald 2011; Leisner 2012). In Oregon, all sites were within the current National Ambient Air Quality Standards (NAAQS), however if these limits are lowered due to reconfiguration of the Act, then cities like Portland, Meford, Eugene, and Salem will go out of attainment (Barnack 2011). 


\section{NOx Chemistry Effects}

There are many other ways that $\mathrm{NO}_{\mathrm{x}}$ effects atmospheric chemistry. Studies generally refer to three groups, $\mathrm{NO}_{x}, \mathrm{NO}_{y}$, and $\mathrm{NO}_{z}$. $\mathrm{NO}_{z}$ refers to nitrogen species that formed of organic nitrates (peroxyacylnitates, alkyl nirates), and inorganic nitrates (nitrate, dinitrogenpentoxide, peroxynitic acid). The entire species grouping of both $\mathrm{NO}_{\mathrm{x}}$ and $\mathrm{NO}_{z}$ are referred to as $\mathrm{NO}_{y}$. There are multiple research groups that are looking into how these compounds effect the environment and the specific chemistry of formation and extinction (A.W. Rollins 2009; Fry 2009; Jones 2010; Tang 2010; Wang 2010). For examples, the Trang group is looking at how $\mathrm{NO}_{3}$ and $\mathrm{N}_{2} \mathrm{O}_{5}$ interact on rate formations of aerosols, while the Fry and Rollins' groups look at the chemistry of the uptake by nitrate radicals and how the affects SOA production (Rollins 2009; Trang 2010). A group from Denmark is looking at how particle amount and composition are affected by $\mathrm{NO}_{\mathrm{x}}$ chemistry, while a group from the UK lead by Jones, looks at how particulate matter is affected by wind and the chemistry of $\mathrm{NO}_{x}$ (Jones 2010). Much information remains to be discovered from these inquiries.

$\mathrm{NO}_{\mathrm{x}}$ and its secondary pollutants are serious problems to both human health and the environment. Studies have shown that short term exposure, termed are a period from 30 minutes to 24 hours, can cause airway inflammation in healthy individuals and increased respiratory symptoms in people with asthma(Agency 2008). $\mathrm{NO}_{\mathrm{x}}$ also influences the formation of PM and Ozone which also have adverse health effects. For 
example, PM is associated with aggravation of asthma, chronic bronchitis, and decreased lung function(Vallero 2008). Ozone has also been found to be a serious irritant to the respiratory system and found to have greater effects in fragile populations like the elderly and children (Agency 2010). Global estimates of long-term $\mathrm{PM}_{2.5}$ have shown that an estimated $89 \%$ of people in the world live in areas that exceed the World Health Organizations air quality guidelines of $10 \mu \mathrm{g} / \mathrm{m}^{3} \mathrm{PM}_{2.5}$ leading to a significant global burden for disease related to air pollution (Brauer Michael 2012).

A significant amount of research has been done, and is being done on the health effects of $\mathrm{NO}_{x}$, and more specifically $\mathrm{NO}_{2}$. For Example, Ute Latza, did a review of the epidemiological studies and experiments done on humans using $\mathrm{NO}_{2}$ as the criteria pollutant. They found moderate evidence that there was a link between short term exposure of 24 hours at a concentration of 50ug NO2/m3, with increased hospital emissions and mortality(latza 2009). They also found that there was a moderate link for susceptible populations including children, adolescents, elderly, and asthmatics for being more susceptible to increased NO2 concentrations even at concentrations below current exposure limits. These results clearly illustrate that $\mathrm{NO}_{2}$ emissions, and thereby $\mathrm{NO}_{\mathrm{x}}$ emissions, pose serious health risks for humans even at concentrations below the NAAQS.

Nitrogen oxides and their products also have a considerable impact on the environment and biological systems. Atmospheric deposition is an important pathway 
for the input of nitrogen species into watersheds and water bodies. However, with the additional nitrogen from $\mathrm{NO}_{x}$ pollution, this can lead to acidification of soils and water from the formation of nitric acid. Also the leaching of nitrogen into surface and ground waters, can cause eutophication and degradation in water quality(Gruber 2008). This is besides the effects from Photochemical Smog and Ozone production that cause damage to the leaves of trees and plants, and may inhibit plant uptake of important nutrients (Agency 2010).

Secondary pollutants produced by $\mathrm{NO}_{\mathrm{x}}$ can cause significant expensive health problems that result in additional expense and loss of productivity. Further, the nitrogen oxides can also cause a variety of ecosystem pollution the effects of which are expensive to mitigate. These and other economic aspects of nitrogen oxide related pollutants contribute to an important effect on the global economy. For example, Joshua Linn, an economist looked at the cap and trade program in the US called the Nitrogen Oxides Budget Trading Program (Linn 2010). In many areas, the cost of electricity is purchased on a wholesale market, which affects not only the price for the energy but also how the costs are spread out to either the producers or consumers. Economists looked at the change in stock prices, and compared that with information with the profit margins of different energy production companies and found that energy producers that rely less on coal, bear less of a financial burden from the program and thus make more profit than companies that rely on coal (Linn 2010). This then pushes the more profitable 
producers to make more of the cheaper energy. This can have interesting consequences for pollution mitigation in that in some case we trade one type of $\mathrm{NO}_{x}$ pollution to another kind of pollution for which less may be known about its atmospheric fates.

Power plants emit large amounts of both nitrogen oxides and sulfur dioxide from (Hewitt 2001). As a large source of specifically $\mathrm{NO}_{x}$ pollution, the effects of legislation and environmentalist pressure are being studied to see what changes cause the biggest differences and the greatest gain for the environment. Due to the restrictions by the Clean Air Act and local governments, many power plants now face caps on the amount of $\mathrm{SO}_{\mathrm{x}}$ and $\mathrm{NO}_{\mathrm{x}}$ they are allowed to emit. A study done in Alabama looked at the effect that emission reductions would have on the Escambia Bay and it's watershed (Vijayaraghavan 2010). The authors of that study found that there was a correlation between $\mathrm{SO}_{x}$ and $\mathrm{NO}_{x}$ emissions. The chemical pathways of $\mathrm{NO}_{x}$ and $\mathrm{SO}_{x}$ however are closely interrelated. Lowing both $\mathrm{NO}_{x}$ and $\mathrm{SO}_{x}$ emissions at the same time results in increased nitrogen deposition from an increase in the ammonia component from the influence of sulfate emissions. There is a $6 \%$ dis-benefit in Nitrogen deposition from the $\mathrm{SO}_{\mathrm{x}}$ reductions. These two chemical pathways work together and are related. It also paints a better picture that the impact of reduction from one pollutant can have on the other.

Current emission rates show that $\mathrm{NO}_{\mathrm{x}}$ emissions may be going down in developed countries, but that emerging or undeveloped counties, $\mathrm{NO}_{\mathrm{x}}$ emissions are 
rising due to an increase in car ownership (Colvile 2001). Recent studies using GOME and SCIAMACHY satellite scans using over the years 1996-2004, found that there was an increase in nitrogen dioxide of about fifty percent over industrial China, which was more than ground inventories had found (Richter 2005). That study also saw a decrease in nitrogen dioxide over parts of the European Union and the United States. Another study done in 2009 used a literature survey along with an emission inventory to show that primary $\mathrm{NO}_{2}$ emissions have increased along roadways in some part of the European Union (Grice 2009). The group predicted that this is due in some part to a change in the type of vehicle that is being used by commercial fleets in the EU. They believe that the compositions of fleets are changing from petrol fuelled vehicles with low $\mathrm{NO}_{2}$ emissions to diesel fuelled vehicles with four times higher emissions and that after market filters oxidize a portion of the $\mathrm{NO}$ to $\mathrm{NO}_{2}$ also raising the concentration.

A study done during the 2008 Olympic Games however, offers a bright picture of the impact that legislation can have on transportation related emissions. During the Olympic Games, China was tasked with reducing it air pollution. They instead implemented strict pollution reduction measures before and during the games that significantly by about $50 \%$ reduced $\mathrm{PM}$ and $\mathrm{NO}_{x}$ emissions (Zhou 2010). Many countries have recently re cognized the importance that controlling $\mathrm{NO}_{\mathrm{x}}$ emissions by implementation legislation that reflect that priority. 
On January 22, 2010, The US EPA created a permissible 1-hour $\mathrm{NO}_{2}$ standard at $100 \mathrm{ppb}$ (Agency 2010). There was no change to the secondary annual standard of 53ppb. Primary standards reflect the need to protect human health, while secondary standards are set to protect public welfare and take into consideration such factors as crop damage, architectural damage, damage to ecosystems, and visibility in scenic areas (Agency 2010). There are also new monitoring and reporting requirements. At least one monitor will be located near a major road in any urban area with more than 500,000 people. A second monitor is required when the city population is greater than 2.5 million or has a road segment with an average daily traffic count of more than 250,000 cars. Also a minimum of one monitor must be in any urban area with a population greater than or equal to one million to asses community wide concentrations. All new $\mathrm{NO}_{2}$ monitors for the program must also be operating by January 1,2013 . These new regulations will help to create a nationwide picture of $\mathrm{NO}_{2}$ levels, and better elucidate the exposure that people are receiving in their cities.

\section{Organic Nitrates and the Formation of the Nitrate Radical}

The nitrate radical is another important product of $\mathrm{NO}_{x}$ chemistry. $\mathrm{NO}_{3}$ is an important nighttime radical that is generated by the oxidation of $\mathrm{NO}_{2}$ by $\mathrm{O}_{3}$ by the following reaction:

$$
\mathrm{NO}_{2}+\mathrm{O}_{3} \rightarrow \mathrm{NO}_{3}+\mathrm{O}_{2}
$$


The rate of production of the nitrate radical can be calculated using the following equation, where $k$ is equal to

During the day, the $\mathrm{NO}_{3}$ experiences rapid photolysis which prevents significant concentrations (Tang 2010). During the night however, appreciable $\mathrm{NO}_{3}$ concentrations can be formed (Perraud 2010).The formation of organic nitrate from the nitrate radical during the night time hours represents an important source of organic nitrate aersols. Organic nitrates are the product of $\mathrm{NO}_{3}$ and alkenes and also between organic peroxy radicals and $\mathrm{NO}$ (Rollins 2010). $\mathrm{NO}_{3}$ plays a significant role in the nocturnal oxidation of some organic race gases including alkenes and dimethylsulphide, and has an impact on the partitioning of $\mathrm{NO}$ and $\mathrm{NO}_{2}$ and $\mathrm{NO}_{y}($ Tang 2010). The reaction of the nitrate radical to form organic aerosols is important because organic nitrates can undergo long-range transport and move the $\mathrm{NO}_{x}$ pollution significant distances from where it was created (Perraud 2010). Organic nitrates exist in both the aerosol and particle phases depending on volatility. Organic nitrates have also been shown to make up $10-20 \%$ of carbon based aerosol mass in urban areas (Day 2010). This is a significant fraction and can have a large impact on measured organic masses of filter samples. 
$\mathrm{NO}_{3}$ and $\mathrm{N}_{2} \mathrm{O}_{5}$ have concentrations that are very closely linked and difficult to separate due to the chemistry of the compounds as evidenced by the following reaction pair:

$$
\begin{aligned}
& \mathrm{N}_{2} \mathrm{O}_{5}+\mathrm{M} \rightarrow \mathrm{NO}_{3}+\mathrm{NO}_{2}+\mathrm{M} \\
& \mathrm{NO}_{3}+\mathrm{NO}_{2} \rightarrow \mathrm{N}_{2} \mathrm{O}_{5}+\mathrm{M} .
\end{aligned}
$$

Both $\mathrm{N}_{2} \mathrm{O}_{5}$ and $\mathrm{NO}_{3}$ are used as radicals in the formation of aerosol nitrate and Secondary Organic Aerosols (SOA). A study by Tang in 2010, found that ambient urban aerosols showed a limited uptake capacity for $\mathrm{N}_{2} \mathrm{O}_{5}$, but were reactive towards $\mathrm{NO}_{3}$ (Tang 2010). The study was trying to elucidate the uptake coefficient for mineral dust with $\mathrm{NO}_{3}$, and found that this did not contribute significantly to nitrate loss in the atmosphere or nitrification of mineral dust. This study shows that the reactive fate for nitrate is still poorly understood.

Secondary organic aerosol refers to the aerosols formed from the breakdown of VOC's by an oxidant with subsequent partitioning to the condensed phase. (Aiken 2008). Aerosols can have a significant effect on human health, visibility and pollution dispersion (Vallero 2008). SOA can account for a significant portion of the troposphere aerosol however the chemical process for formation are poorly understood (Hallquist 2009). Organic material is a large amount of the particulate matter found in the atmosphere and affects the scattering of light and cloud composition. The total of 
secondary organic aerosols can have a very large impact on the environment and is of special concern due to its relationship with $\mathrm{NO}_{\mathrm{x}}$. Nitrate is postulated to be an important oxidant for the nighttime breakdown of VOC's into secondary organic aerosols (Fry 2009). Recent research into the chemical reaction of nitrate has studied its effect on SOA formation and found large yields (Fry 2009). $\mathrm{NO}_{\mathrm{x}}$ chemistry could however provide a large source of oxidants to be used in SOA formation.

\section{FTIR Spectroscopy}

Due to the complexity of the atmosphere, many techniques are employed for analysis of atmospheric composition. Analysis in the past has included gas chromatography-mass spectrometry (GC/MS), however GC/MS can only quantify 10$50 \%$ of the organic mass in aerosols and needs a large sample mass and complicated derivatization procedures (Coury 2008). Fourier transform infrared spectroscopy (FTIR) is an excellent approach for analyzing atmospheric particles as it is non-destructive, can provide high sensitivity, and is precise (Zhao 2010). Early studies with FTIR showed a great improvement of functional analysis over GC/MS (Allen 1994). FTIR can also be used as a way to select for specific organic functional groups like organic nitrates (Day 2010). The technique of FTIR represents a way to have quantitative measurements of specific functional organic groups that is only limited by the sampling size of the filters themselves(Rollins 2010). 
FTIR has become an analytical technique that can measure organic compounds and identify functional groups (Coury 2008). The use of FTIR has also developed into a way to discover specific VOC reaction pathways and provide a constraint on the products that can form under atmospheric conditions(Russell 2011). FTIR using attenuated total reflection (ATR-FTIR) is one of the three most commonly used FTIR techniques (Zhao 2010). In ATR-FTIR, particles, either dry or in solution, are deposited on a horizontal crystal, in this case a diamond ATR crystal, for analysis. The signal from the infrared rays is reflected in the ATR crystal where it can penetrate into the sample with an effective path length of at least a few micrometers and then reflected back towards a detector (Zhao 2010). FTIR analysis of organo-nitrate peaks allows for the specific quantization at three peaks, $1630 \mathrm{~cm}^{-1}, 1280 \mathrm{~cm}^{-1}$, and $860 \mathrm{~cm}^{-1}$ (Day 2010). FTIR has been used by many groups to show organic functional group characterization (Polidori 2008; Coury 2009; Day 2010; Zhao 2010; Russell 2011).

\section{Columbia River Gorge}

The Columbia River Gorge (CRG) acts a matchless environment to conduct laboratory aerosol composition experiments in a flow tube like environment. The CRG is situated with large sources of primary pollutants at either end. To the west of the CRG is the large metropolitan region of Portland Oregon, and Vancouver Washington. According to the 2010 census, this region contains the largest city in the state of Oregon 
and the fourth largest city in the state of Washington. The total population of the metropolitan area is more than 1 million people.

It is well understood that metropolitan regions result in high concentrations of greenhouse gasses and the Portland region is no different with emissions inventories of 8.5 million metric tons of $\mathrm{CO}_{2}$ equivalent (Rice 2011). Metropolitan areas are also significant sources of $\mathrm{NO}_{\mathrm{x}}$ from fossil fuel burning, which leads to a production of ozone. A study done by the Rice group found that measured concentrations of $\mathrm{CO}_{2}$ were lower upwind of Portland in the summer and showed the effect that traffic pollution had on concentrations (Rice 2011).

Previous reviews of research (Gaffney, 2009) have shown that combustion related emissions have a significant impact on aerosol formation and climate and have also shown the broad impact that the transportation sector has on human health and air pollution (Colvile, 2001). This illustrates the importance of understanding the fate of these primary pollutants. To the east of the CRG, the Boardman power plant, a large Concentrated Animal Feeding Operation(CAFO), and several agricultural farms and nurseries supply the gorge with several sources of primary pollutants (Green 2001). Power plants are a significant source of $\mathrm{NO}_{2}$ and $\mathrm{SO}_{2}$ pollution (Vijayaraghavan 2010), while CAFO's and agricultural activities are a significant source of ammonia and VOC's (Fenn 2010). These pollutants play a significant role in aerosol chemistry and secondary organic aerosol production. 
Due to the east-west orientation of the gorge and typical regional airflow patterns, winds blow through the gorge in opposite directions during summer and winter seasons (Sharp 2004). So, during the summer time, winds blow through Portland and down the gorge to the east (Green 2008). During the winter time, the winds blow from the Boardman power plant, past a CAFO through the gorge to Portland. These pollutants entrained in these flows tend to include $\mathrm{NO}_{x}$ from the city or power plant, $\mathrm{NH}_{3}$ from the animal feed lot and VOC's from anthropogenic sources and tree emissions in the gorge.

\section{The Columbia River Gorge as a Flow Tube}

$\mathrm{NO}_{\mathrm{x}}$ represents a significant amount of air pollution transported into the CRG. The emissions comes from a variety of sources, with the primary anthropogenic sources being from transportation related process and energy production. These $\mathrm{NO}_{\mathrm{x}}$ compounds cause severe health and ecosystems effects. Understanding how $\mathrm{NO}_{\mathrm{x}}$ compounds are formed, what the sources are, their effects and current regulations, paints a reveling picture of a current air quality issue with a significant impact on the human life.

Research that was done as part of the Causes of Haze in the Columbia River Gorge (COHAGO,Green, 2008) estimated that as western winds travelled down then gorge, they brought with them a "pulse of hazy air" from the metropolitan area. In the COHCRG Report, measurements of light scattering at eight sites showed that when using 
a cluster analysis of common wind patterns, they could characterize some of the main wind patterns seen in the gorge (Green 2007). In these statistical clusters, a plume of particles that scatter light is seen to peak at time intervals that travel down the gorge from Portland. Other research done by the Jaffe group using 14 years of IMPROVE data found that $\mathrm{PM}_{2.5}$ on easterly wind days was closely correlated with the operation of the coal-fired power plant at Boardman (Jaffe 2009). This suggests that when the wind is flowing east to west, pollution is being transported down the CRG.

\section{Objective}

The effects of transportation air pollutants emanating from the Portland Metropolitan area on air quality in the Columbia River Gorge are poorly understood. This study aims to characterize these concentration effects on organic nitrate production. This information will shed light on the fate of nitrogen downwind of Portland. Using the technique of FTIR to characterize the organic nitrate functional groups and then draw correlations between the FTIR data and the ambient gases, will help to illuminate the chemical reactions that may be happening as pollution is transported down the gorge. This also allows for connections to be drawn between meteorological conditions and concentrations of pollutants. Understanding the nitrogen chemistry that happens in the CRG will support both pollution prevention and mitigation efforts. 


\section{Methods}

\section{Overall Approach}

The study incorporates a field study and analytical and statistical analysis. NO,

$\mathrm{NO}_{2}, \mathrm{O}_{3}$, and meteorological data were collected over two 15-week periods, in the

summer of 2010 and the summer of 2011 (see Table 1). Field particulate samples were

collected on glass fiber filters through a High-Volume particle sampler, solvent

extracted, and analyzed using FTIR. The gas-phase ambient data, along with the

collection and extraction of the high-vol filters, offer a descriptive picture of the ambient

air in the Portland area.

Table 1 Dates for the summer of 2010 and 2011 sampling periods

\begin{tabular}{|l|l|}
\hline \multicolumn{1}{|c|}{ Sites } & \multicolumn{1}{c|}{ Dates } \\
\hline DEQSEL* & $6 / 24 / 10-10 / 14 / 10$ \\
\hline Reed College & Summer 2010 \\
\hline Mt. Zion & $6 / 24 / 10-10 / 3 / 10$ \\
\hline DEQSPR* & $6 / 1 / 2010-9 / 30 / 2010$ \\
\hline \hline DEQSEL* & $7 / 19 / 11-10 / 30-11$ \\
\hline Reed College & Summer 2011 \\
\hline Mt. Zion & $7 / 21 / 11-10 / 28 / 11$ \\
\hline DEQSPR* & $6 / 1 / 2011-9 / 30 / 2011$ \\
\hline Beacon Rock & $6 / 29 / 11-11 / 30 / 11^{* *}$ \\
\hline
\end{tabular}

*Maintained by the ODEQ

**Some gaps due to power loss and instrument error 


\section{Sample Sites}

Table 2 Specific Site locations, including latitude and longitude.

\begin{tabular}{|l|c|c|l|l|}
\hline \multicolumn{1}{|c|}{ Sites } & Latitude & Longitude & \multicolumn{1}{|c|}{ Nearest City } & Site Description \\
\hline DEQSEL, SE Lafayette & 45.49660 & -122.602900 & Portland, OR & Urban \\
\hline Reed College & 45.48123 & -122.626921 & Portland, OR & Urban \\
\hline Mt. Zion & 45.56924 & -122.210381 & Washougal, WA & Rural \\
\hline DEQSPR, Carus & 45.25930 & -122.588000 & Canby, OR & Rural \\
\hline Beacon Rock & 45.61926 & -122.026998 & Stevenson, WA & Rural \\
\hline
\end{tabular}

There were two sampling sites in the summer of 2010 at Reed College and Mt.

Zion. The Reed College sampling site is located in the middle of a suburban residential area near a riparian area. The Mt. Zion site is located east of Portland Oregon in the gorge, in a large field near the Washington Highway SR-14. The selection of these sites allowed for both simultaneous comparison of an urban and near-field rural site, and for comparative analysis of chemical composition of the aerosol phase. The Reed College site was chosen due to its proximity to the DEQ field station monitor at SE Lafayette in residential Portland. Ambient gas-phase concentration data was sourced from the DEQ Southeast Lafyette site. The Mt. Zion site was selected because it not only represents a near-field rural site, but it is also the site of Federal IMPROVE sampling and offered a unique site with past air quality history available. All sites supported secure sampling with little interruption. 


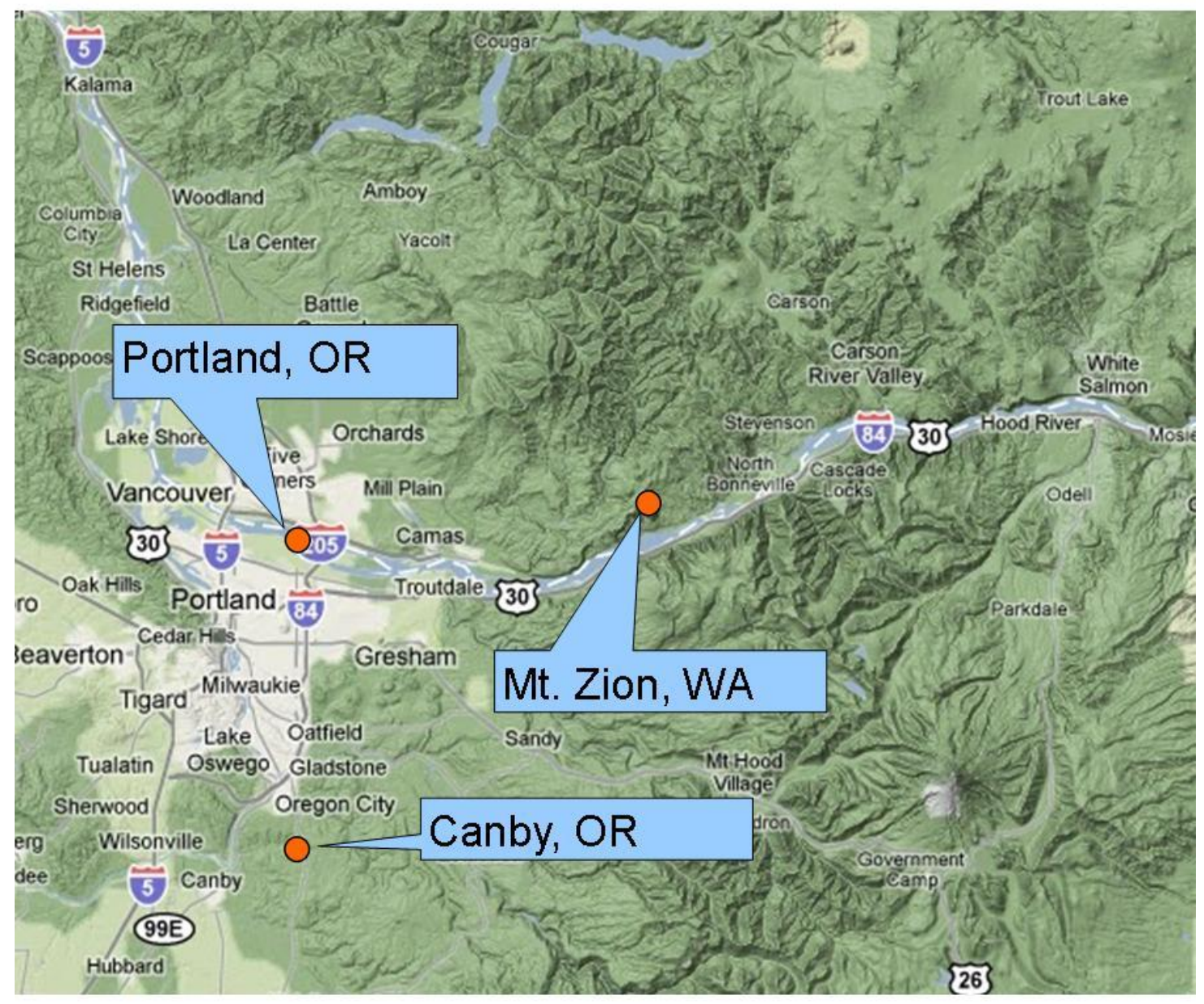

\section{Figure 1 Map of Sampling Sites}

There were three sampling sites at Reed College, Mt. Zion, and Beacon Rock

State Park during the summer of 2011. The additional 2011 site, Beacon Rock, was

chosen for its location further downwind of the Mt. Zion site. This site was located in the storage closet in the park restrooms near a large field. All sampling sites were equipped with electricity and offered limited access to other people allowing for significant control over filter exposures and little interferences with ambient measurements. 
As seen in Table 3, each site has very specific unique characteristics in addition to the sampling parameters. The MT. Zion site located in the CRG is located up on a bluff in the middle of large fields. During the summertime these fields are filled with wildflowers. During both the summer of 2010 and 2011 saw several wildfires in the CRG. The Portland site at DEQSEL is located in the center of several major roads, including Highway 26, and I-205. The Canby site is located in the center of several active agricultural fields. This information is reflected in Table 3.

Table 3 Site Descriptions illustrating the area around the sampling site

\begin{tabular}{|l|l|}
\hline \multicolumn{1}{|c|}{ Sites } & \multicolumn{1}{c|}{ Site Description } \\
\hline DEQSEL & Residential Area, located between two homes \\
\hline Reed College & Residential area, located at Chemistry building near riparian area \\
\hline Mt. Zion & Rural Area, located in large empty field near to a gravel road and SR-14 \\
\hline DEQSPR & Rural Area, located near large agricultural field \\
\hline Beacon Rock & Rural Area, located in park area near a large field at river level \\
\hline
\end{tabular}

\section{Sample Collection Overview}

Ambient sampling parameters at the sites included wind speed, wind direction, temperature, and relative humidity. Measurements also included bscat, $\mathrm{NO}, \mathrm{NO}_{2}$, and $\mathrm{O}_{3}$. At the Mt. Zion site, a Hi-Vol was set up along with ambient atmospheric measurements. A Hi-Vol was set up at the Reed College site. 


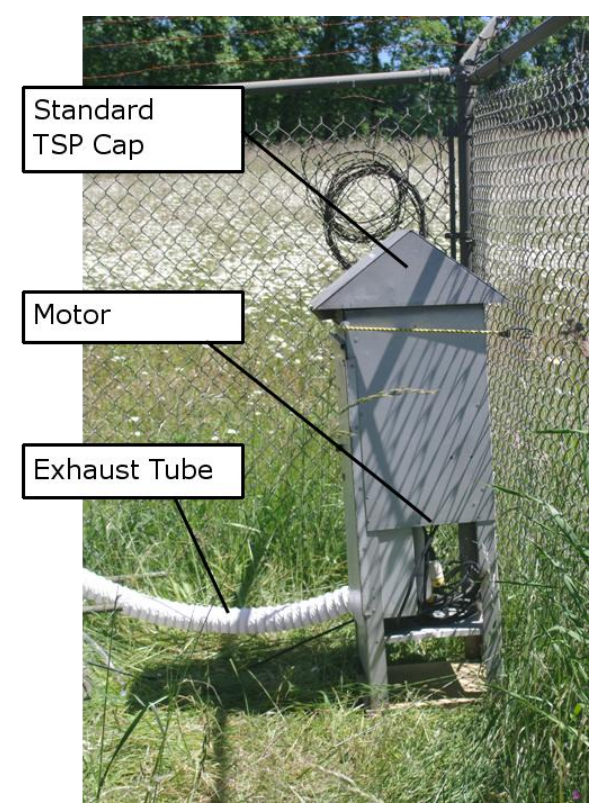

Figure 2Tisch Hi-Vol Set-Up at the Mt. Zion Site.

Ambient measurements for the city of Portland were taken from the Oregon Department of Environmental Quality Portland Air Quality Site at S.E. Lafayette. This site is the official National Air Toxics Assessment (NATA) site for monitoring and compliance in the city. In the summer of 2011 , bscat, $\mathrm{O}_{3}$, wind speed, wind direction, temperature, and relative humidity were measured at the Beacon Rock site. The first sampling period was from June 24, 2010 until October 3, 2010. During the 2010 15-week period, 10 filter samples were taken simultaneously at Reed and Mt. Zion. Blank filters were either exposed in the field or in the lab for each sampling date. The second sampling period was from July 19, 2011 until October 16, 2011. During this 10-week period, 9 filter samples were taken simultaneously at Reed and Mt. Zion. 


\section{Ambient Measurements}

Table 4 Specific site instrumentation for each equipment location

\begin{tabular}{|l|l|l|}
\hline \multicolumn{1}{|c|}{ Sites } & Hi-Vol & \multicolumn{1}{c|}{ Ambient Instumentation } \\
\hline DEQSEL & No & NOx Analyzer, Ozone, Nephelometer, Anemometer, Met. Station \\
\hline Reed College & Yes & \\
\hline Mt. Zion & Yes & NOx Analyzer, Ozone, Nephelometer, Anemometer, HOBO \\
\hline DEQSPR & No & Ozone, Nephelometer, Met. Station \\
\hline Beacon Rock & No & Ozone, Nephelometer, Anemometer, HOBO \\
\hline
\end{tabular}

$\mathrm{NO}$ and $\mathrm{NO}_{2}$ were measured using a Thermo Environmental NO-NO2 -NOx

Analyzer. $\mathrm{NO}$ is measured quantitatively using a chemiluminescent reaction with $\mathrm{O}_{3}$. In

a second channel, $\mathrm{NO}_{2}$ is converted to $\mathrm{NO}$ using a Molybdenum catalyst at high

temperature giving a total $\mathrm{NO}_{x}$ value from which $\mathrm{NO}_{2}$ can be determined subtractively .

Ozone was collected at the sites using a Dasibi Environmental Corp Ozone Analyzer. The $\mathrm{O}_{3}$ is calculated by measuring the absorption of UV light in an ambient air sample. Both $\mathrm{NO}_{\mathrm{x}}$ and Ozone boxes were calibrated before sampling periods at the Oregon

Department of Environmental Quality Laboratory. The first calibration was done in May of 2010, and the second calibration was done in June of 2011. Bscat was collected on a Radiance Research Integrating Nephelometer. This was measured by passing the ambient air sample through a reflective cavity. Light scatter caused by the particulate matter in the sample is measured and converted to a scattering coefficient.

Nephelometers were calibrated with zero air at the lab before deployment both summers. Wind speed and wind direction were recorded from a Young SE Anemometer while relative humidity and temperature information was collected by a HOBO Temperature Logger. Two Tish Environmental Instrumentals Hi-Vols that were donated 
by the Oregon DEQ, were used to collect the filter samples. The Hi-Vols were calibrated at the Oregon Department of Environmental Quality Laboratory in June 2010. Both samplers were calibrated for a $50 \mathrm{~L} / \mathrm{min}$ flow and ran at $50 \mathrm{~L} / \mathrm{min}$ in the field.

\section{Filter Extraction}

The extraction method used was derived from the extraction method used by the Polidori group (Polidori 2008) and also using the EPA TO_13A standard method for extraction semi-volatiles on a PUF material (EPA 1999). Several changes were made to the method, including changes in using a 25\% Dichloromethane, 25\% Hexane, and 50\% Acetone extraction solvent, with boiling chips to promote even boiling and extraction, a set cook time of 18 hours, and glassware preparation step.

Hi-Vol samples were collected on 8inch by 10 inch glass fiber filters (Pall Corporation, Type A/E Glass Fiber Filter P/N 61638). To begin filter collection, filters were placed on a scale and left to equilibrate at room temperature for at least 15 minutes. The filter was then weighed to the nearest ten thousandths. After the filter had been weighed, it is stored at room temperature in an aluminum sleeve until use. Filters were then carefully loaded onto the Hi-Vol samplers using gloves and tweezes, with care being taken to not touch or rip the filter. A filter was weighed for each site along with a blank that was noted as either a field or lab blank. Filters noted as lab blanks were left in aluminum sleeves in the fridge. Filters that were noted as field blanks were placed in aluminum filters and left in the sample transport box at the site. All sample filters were 
run on a timer for a period of 24 hours concurrently. Filters were then carefully transferred to a labeled aluminum sleeve and stored at $4^{\circ} \mathrm{C}$ until extraction.

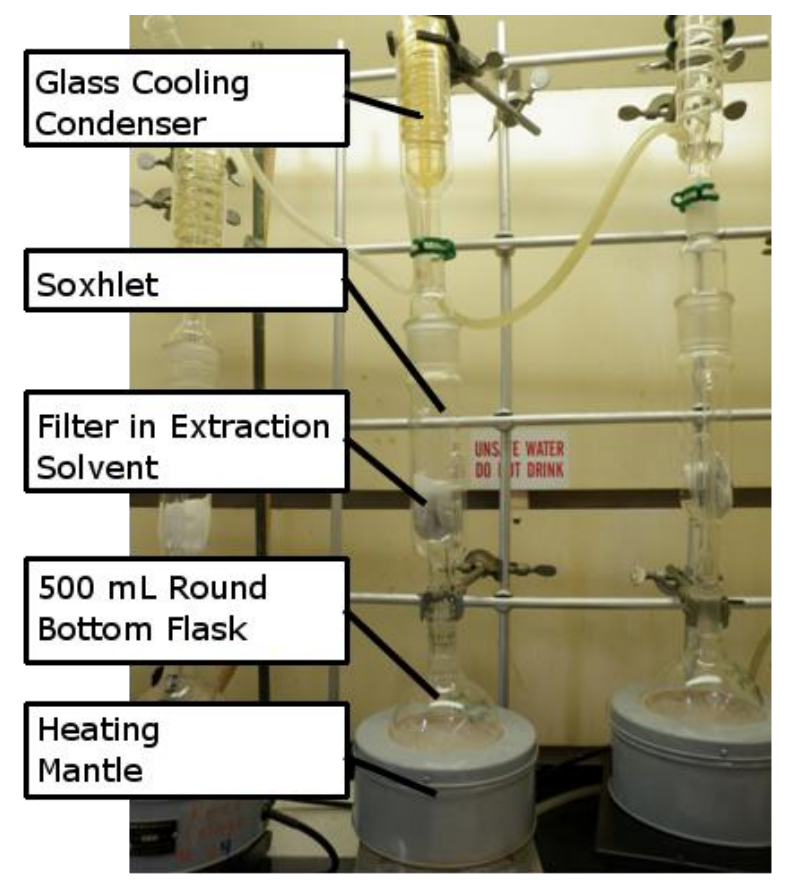

Figure 3 Soxhlet extraction set-up at Reed College.

The filters were extracted by a Soxhlet extraction using the $25 \%$

Dichloromethane, 25\% Hexanes, and 50\% Acetone extraction solvent. In preparation for the extraction, glassware was first hand washed in hot soapy water and rinsed three times in both hot water then DI water. Glassware was then cooked in an oven at $150^{\circ} \mathrm{C}$ for at least one hour. After glassware was taken out and cooled it could then be set up. A $500 \mathrm{~mL}$ glass round bottom was placed in a heating mantle. 3-5 boiling chips were then placed in each round bottom. A glass Soxhlet condenser was placed in each round bottom. The filter was then roughly folded into a 4 inch square and using tweezers gently placed into the bottom of the Soxhlet. $225 \mathrm{mLs}$ of the $25 \%$ Dichloromethane, $25 \%$ 
Hexanes, and 50\% Acetone extraction solvent was added to each sample through the top of the soxhlet. Samples were then capped with a glass condenser and allowed to reflux for a period of $24 \pm 2$ hours. After allowing the samples to cool in the round bottom, extracts are concentrated rapidly in a rotary evaporator, with sides being rinsed down in acetone. Samples were then blown down to about $2 \mathrm{~mL}$ using a pure nitrogen stream. Samples were then filtered through a $0.2 \mu \mathrm{m}$ Teflon filter to remove excess filter particulate. Samples were rinsed with acetone again to bring them up to a volume of 3 $\mathrm{mLs}$. Samples were blown down to a final measured volume of $1 \mathrm{~mL}$. After extraction, samples are stored in a refrigerator at $4^{\circ} \mathrm{C}$ to prevent degradation of the semi-volatile species.

\section{Filter Analysis using FTIR}

Samples were analyzed on a Thermo IR 300 IR Spectrometer with a Diamond ATR Crystal and a deutratedtriglycine sulfate (DTS) detector. This allowed for identification of three separate nitrate peaks related to the organonitrate. Samples ran during the summer of 2010 were analyzed with a purge flow of pure nitrogen at $30 \mathrm{~L} / \mathrm{min}$. Samples ran during the summer of 2011 , were analyzed with a purge flow of dry air at $30 \mathrm{~L} / \mathrm{min}$. A background at pure nitrogen and pure dry air were overlaid to check for contamination problems and showed no difference. Each day of FTIR analysis, a new background was taken. The FTIR was prepped for each sample by cleaning the crystal with acetone, sonicating the sample holder with acetone for three minutes, and then blowing the FTIR 
bench dry with air for 30 minutes. Afterwards, $50 \mu \mathrm{L}$ (precise volume determined by a calibrated 10-100 $\mu \mathrm{L}$ pipette) of sample was placed on the crystal and allowed to dry for 30 minutes prior to spectrum collection.

\section{FTIR Data Analysis}

FTIR Spectra from each sample was analyzed using EZ Omnic the FTIR software for data analysis (Thermo Scientific). Daily blanks were subtracted from the sample signal, then the spectrum was baseline corrected. Spectral peaks were located and the area under the peak was integrated by hand. The peaks of interest were the broad hydroxyl peak at $3350 \mathrm{~cm}^{-1}$, the alkane peaks around $2920 \mathrm{~cm}^{-1}$, and three organonitrate peaks at $860 \mathrm{~cm}^{-1}, 1280 \mathrm{~cm}^{-1}$, and $1630 \mathrm{~cm}^{-1}$. The integration bounds for selected peaks were determined individually for each spectrum, as they depend on intensity of neighboring peaks.

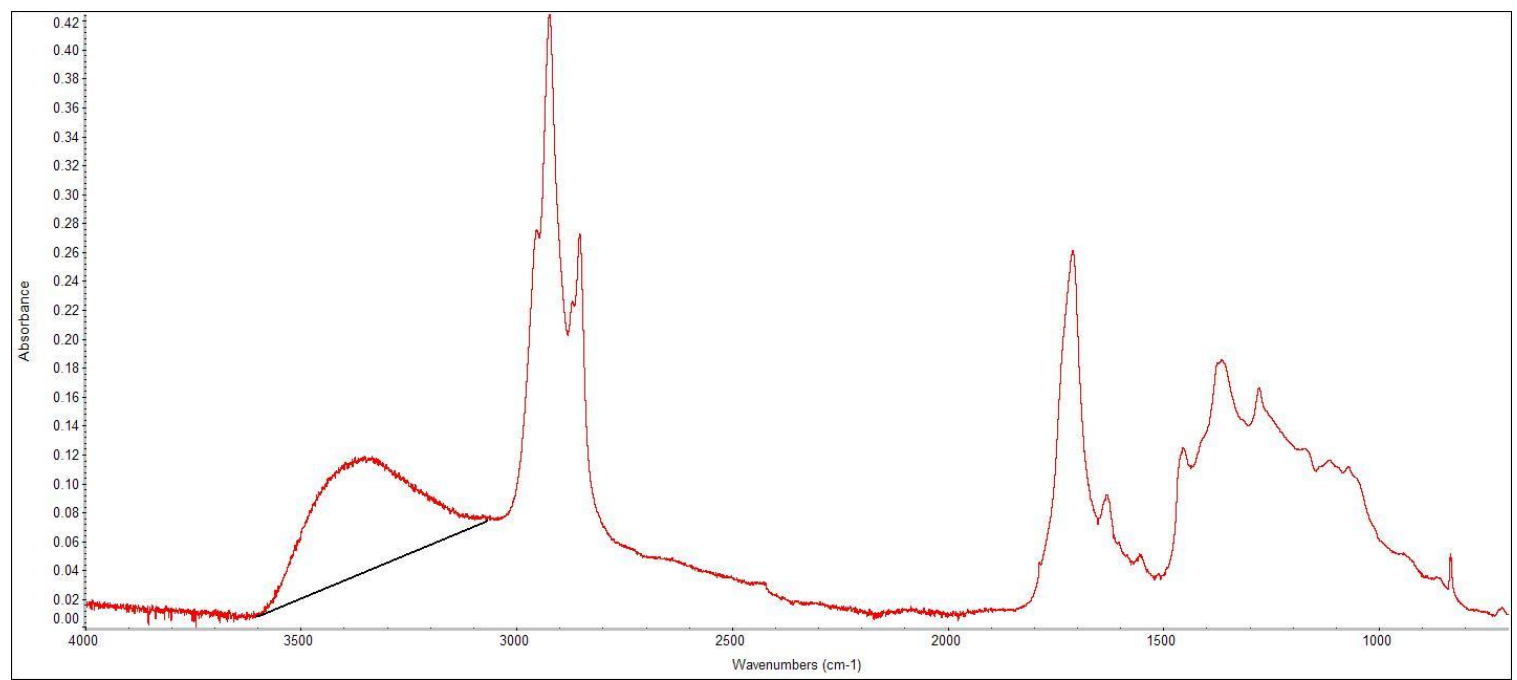

Figure 4 An example of spectra peak integration by hand. 


\section{Statistical Analysis of the Ambient Measurements}

To aggregate ambient gas-phase data into a smaller working pool, the ambient data was first binned to five minute averages for each individual parameter. To remove instrument outliers, data points that were roughly 2 times higher than the 1-hour maximums as posted by DEQ were removed. So for example, at DEQ SEL, the 1-hour maximum for Ozone was $105 \mathrm{ppb}$ on 8/19/2010. So Ozone points that were above 200 ppb were removed from the averages. Outliers were only removed on Ozone, NO, and $\mathrm{NO}_{2}$ data. Data acquired during times of instrument maintenance was removed. There were two incidences of major data loss due accidental disconnection of the analogue to digital converter to the computer, by outside parties.

To find the average wind speed and wind direction for a day, the north-south and east-west components of the wind speed vector needed to be separated. The following equations were used were $N_{v}$ is the northerly vector, $E_{v}$ is the easterly vector, $S$ is wind speed, and $\theta$ is the angle of wind direction from the north.

All of the $N_{v}$ and $E_{v}$ are then averaged for the day. Average direction, is then the vector with direction included. 
Average velocity is found using the Pythagorean Theorem and the average northerly and easterly vectors.

\section{Classification by wind direction}

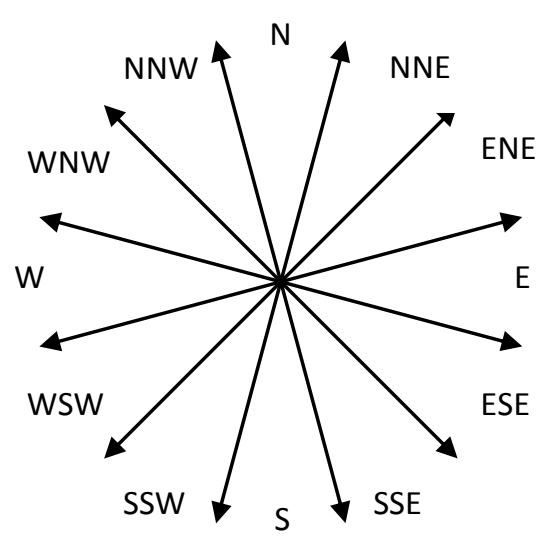

Figure 5 Wind direction breakdown by the 12 wind classifications.

To organize the ambient data, days were broken up into classifications based on counts of wind direction weighted by wind velocity. There were 12 classifications, accounting for $30^{\circ}$ of the wind rose. For each day, each individual average was classified based on its direction the sum of all the velocities classified in each direction was taken, the direction with the highest sum of velocities was assigned as that days classification. This allowed for a greater degree of analysis and the ability to see specific impacts on each direction. 


\section{Results}

The major findings of this work show several important associations between the ambient data and the FTIR analysis when looking at the production of organic nitrates. A relationship was found between wind direction and concentrations of ozone and b-scat at the Portland and Mt. Zion sites. The results also show the correlation between organic nitrate aerosols and the nitrate radical formation. This data illustrates the connection between the ambient variables and the integrated organic nitrate area, which gives us information on the production of organic nitrates and the nitrate radical. Both ambient data and filter quantification were used for analysis. 
Wind Direction Classification Patterns

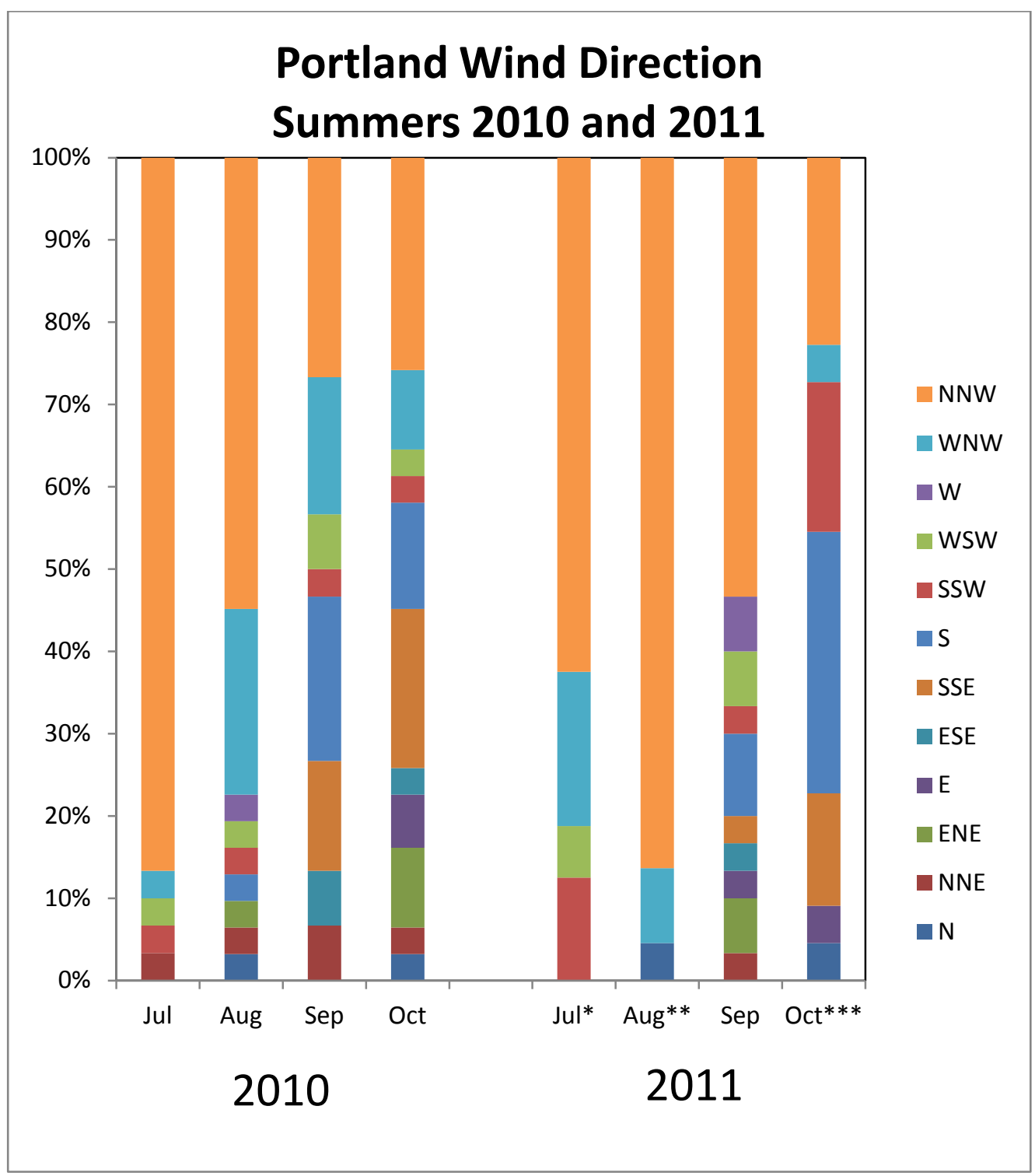

Figure 6 Wind direction classifications in Portland Oregon during the summers of 2010 and 2011.

Figure 6 shows the wind direction classifications at the Portland Oregon sampling site. The summer of 2010 shows that the wind came from the NNW for most of the 
sampling period. During the month of July $2010,86.67 \%$ of the wind came from the NNW alone. The summer of 2011 also shows a pattern of winds coming primarily from the NNW. There are several missing days during the summer of 2011, this information is noted in Table 1 and Table 5. 


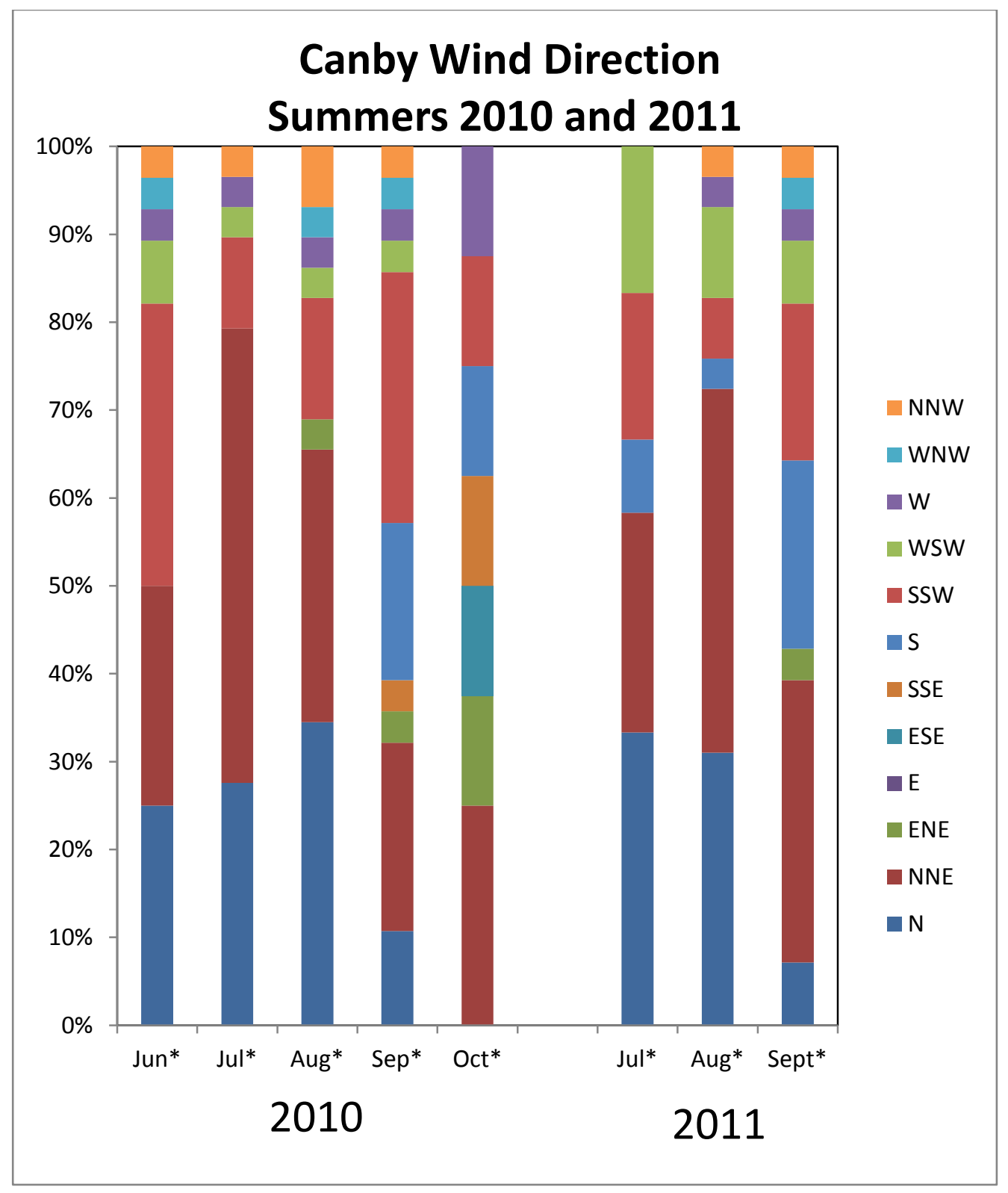

Figure 7 Wind direction classifications in Portland Oregon during the summers of 2010 and 2011

The Canby wind data shows that during the summer of 2010, most of the wind was coming from the NNW. This would be pushing pollution from the Portland area towards the sampling site to the south-east. The summer of 2011, shows very similar 
wind patterns to the summer of 2011. There is a high incidence of wind coming from the NNW. There are several missing periods of data during this period as noted in Table 5.

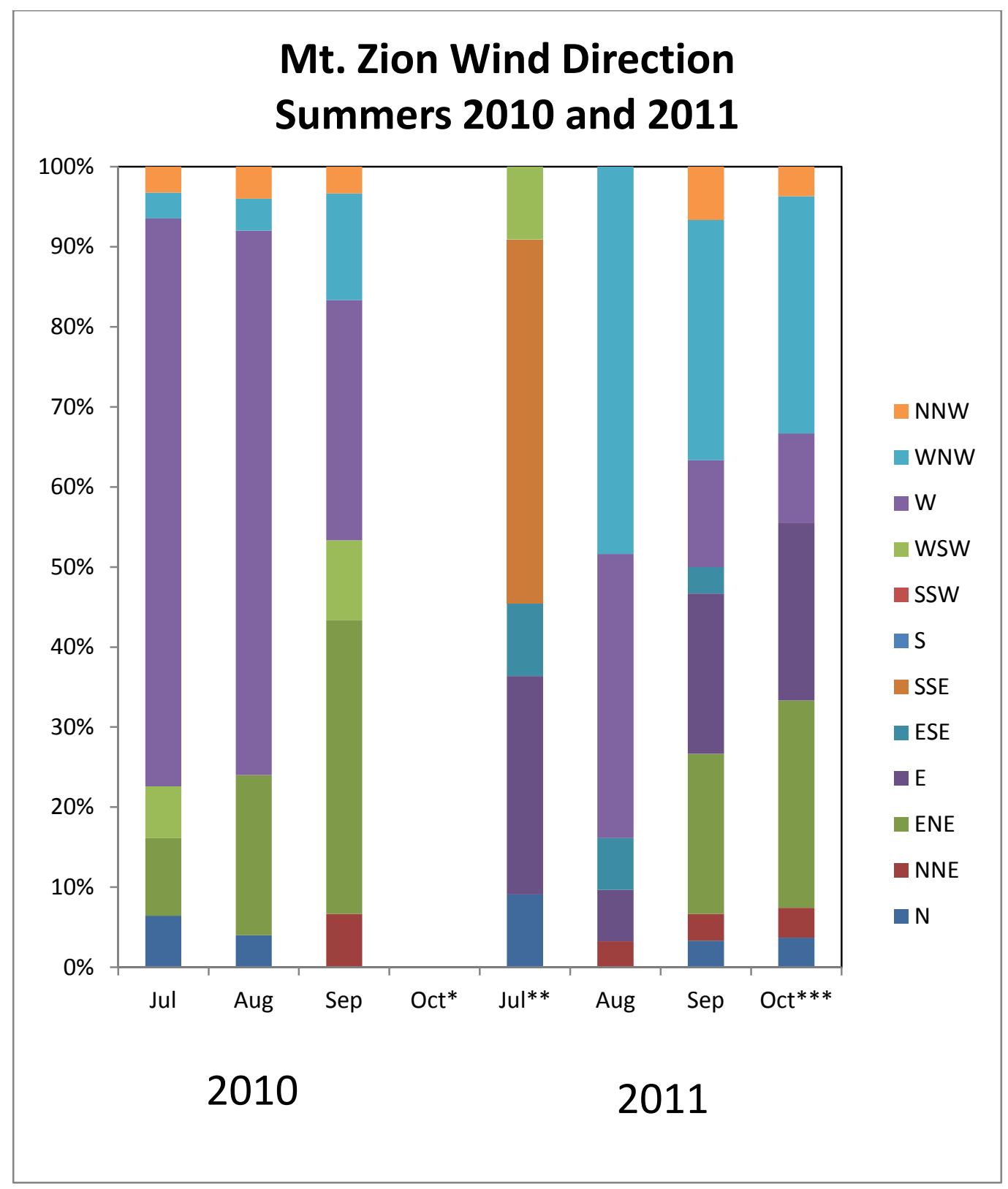

Figure 8 Wind direction classifications in Mt. Zion Washington during the summer of 2010 and 2011. 
The Mt. Zion wind data shows that during the summer of 2010, most of the wind was coming from the west and some from the WSW. This would have a strong influence on pollution levels from nearby forest fires and from Portland Oregon. The summer of 2011, a greater mix of wind patterns from the summer of 2010. There is wind coming from the west, but also some from the north, specifically the north-north-west, and west-north-west. There are several missing periods of data during this period. This is noted in Table 5.

Table 5 The number of days in each month in which ambient B-Scat data was available

\begin{tabular}{c|cccc} 
& Month & Portland & Mt. Zion & Canby \\
\hline & Jun & & & 28 \\
& Jul & 30 & 31 & 29 \\
\multirow{2}{*}{} & Aug & 31 & 25 & 29 \\
& Sep & 30 & 30 & 28 \\
& Oct & 31 & & 8 \\
& Aug & 22 & 31 & 29 \\
\multirow{2}{*}{} & Sep & 30 & 30 & 28 \\
\hline \multirow{2}{*}{} & Oct & 22 & 27 & \\
\hline
\end{tabular}




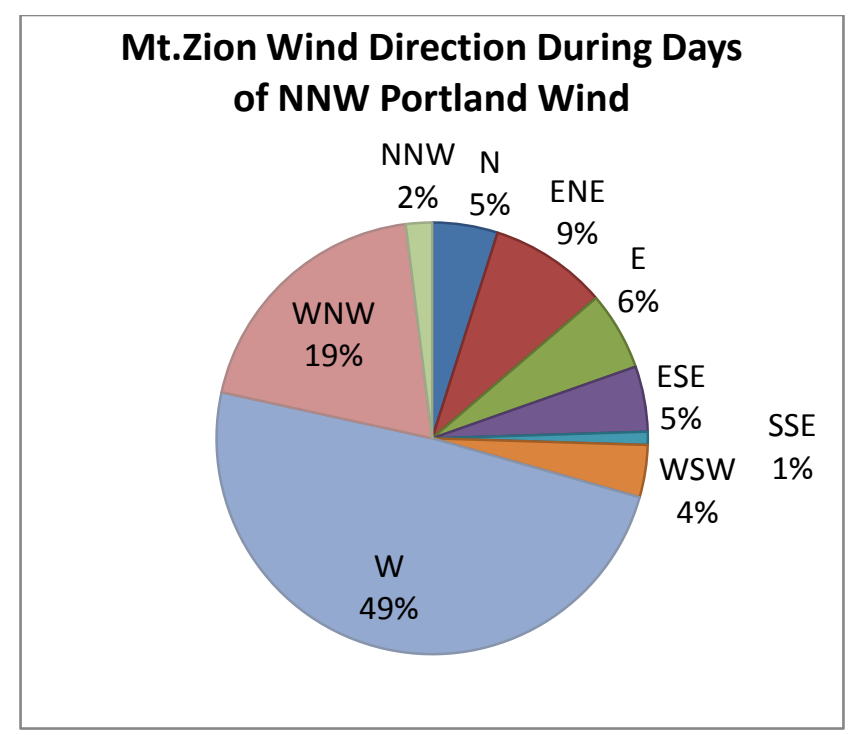

Figure 9 The wind direction at Mt. Zion is predominantly west when the wind direction is NNW in Portland. 


\section{Wind Direction and B-scat}

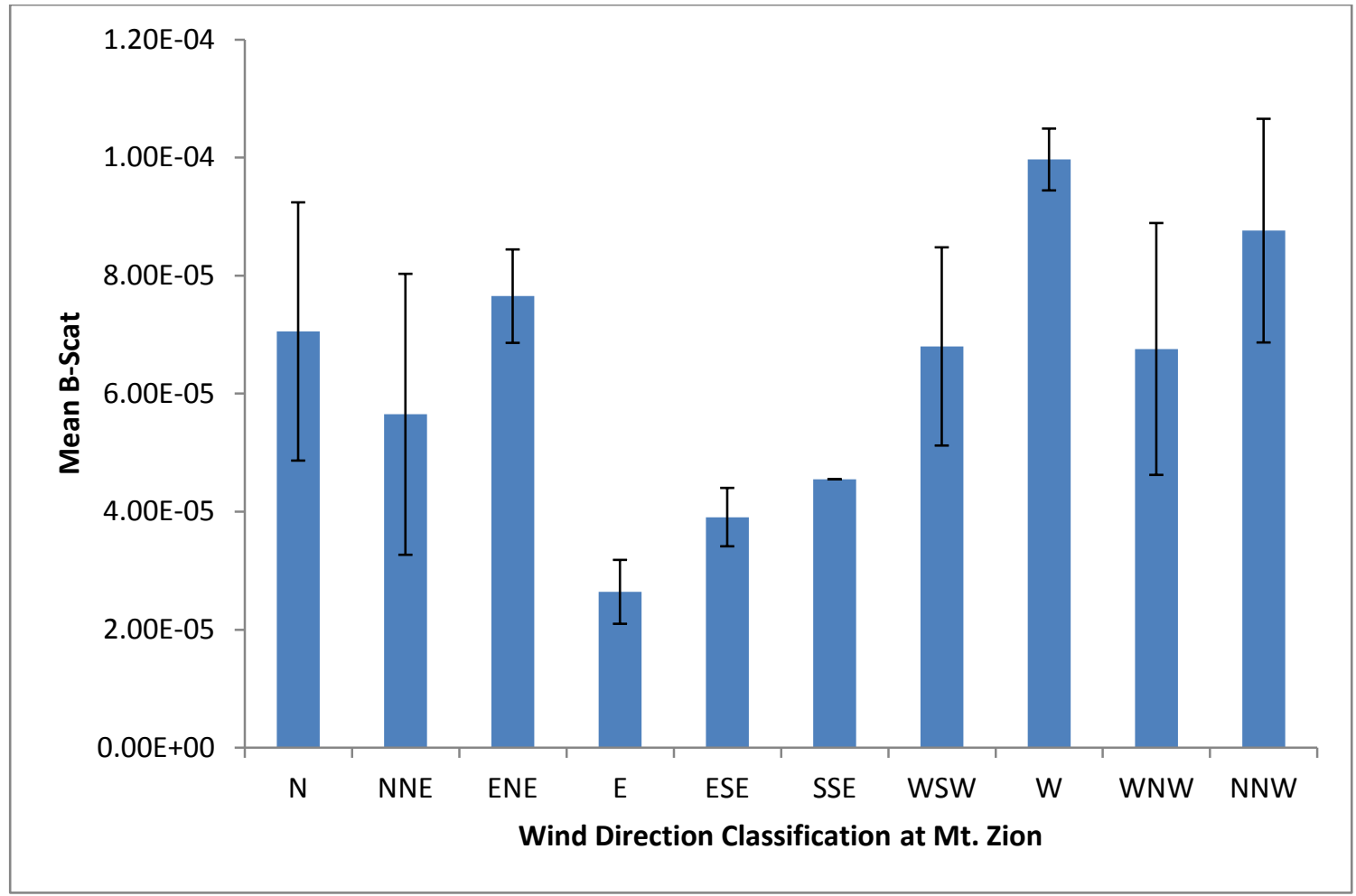

Figure 10: Average levels of B-scat by wind direction at Mt. Zion Washington over both sampling summers. Error bars indicate standard error.

Figure 10 above shows the average B-scat by type of wind day. This shows that on days when the wind comes from the west the B-scat is the highest. On days when the wind comes from the east and east-south-east, the b-scat is the lowest. 


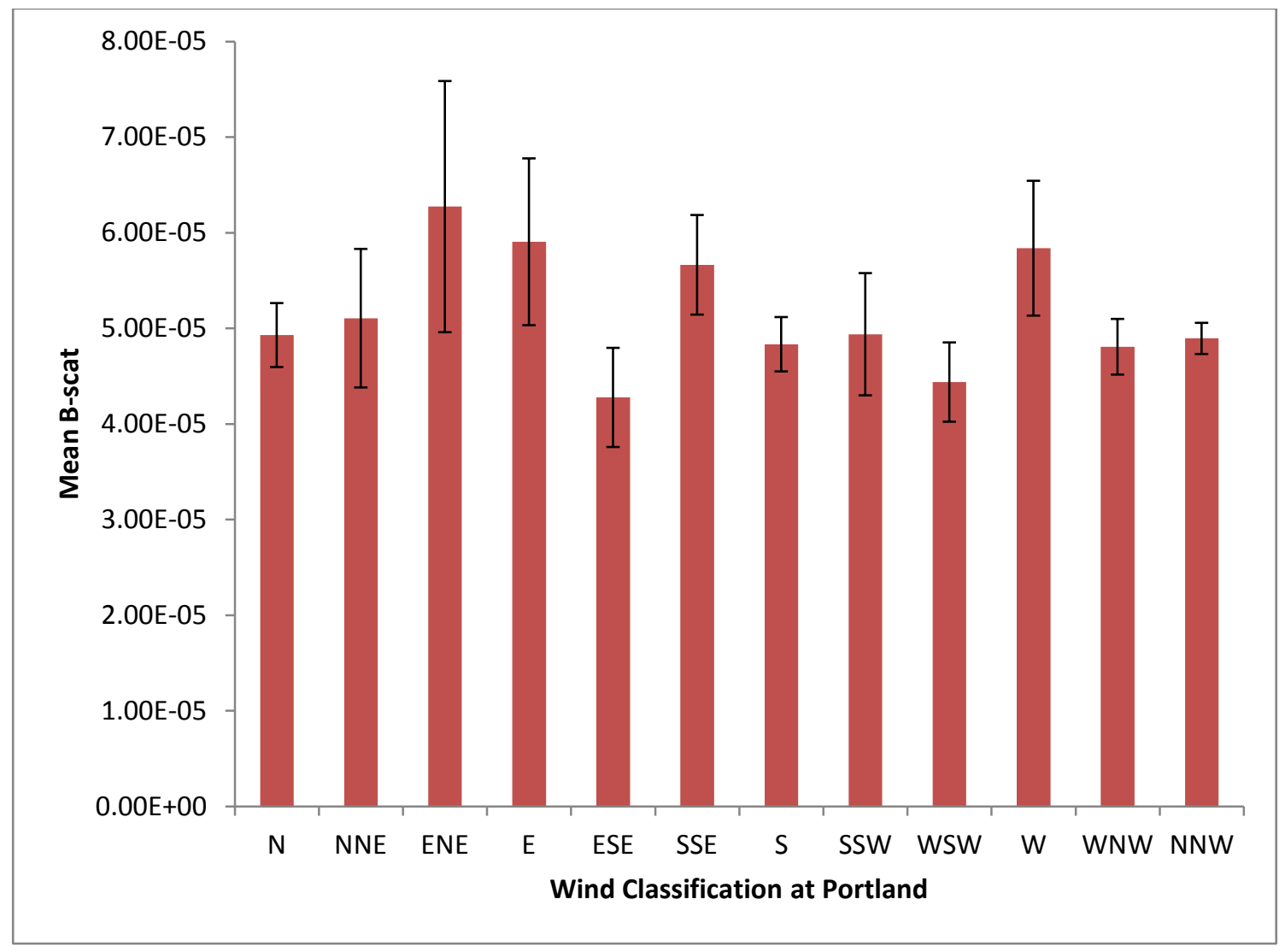

Figure 11 Average Daily B-scat by wind classification at the Portland Oregon site. Error bars indicate standard error.

The average daily B-scat at the Portland Oregon site shows some higher b-scat when the wind direction is from the east and east-north-east. This is reflected in Figure 11. The b-scat will be highly influenced though by local topography and location. The site is located near three major transport arteries, so the b-scat may not be closely related to wind direction. The overall b-scat at this site is lower than at the Mt. Zion site. 


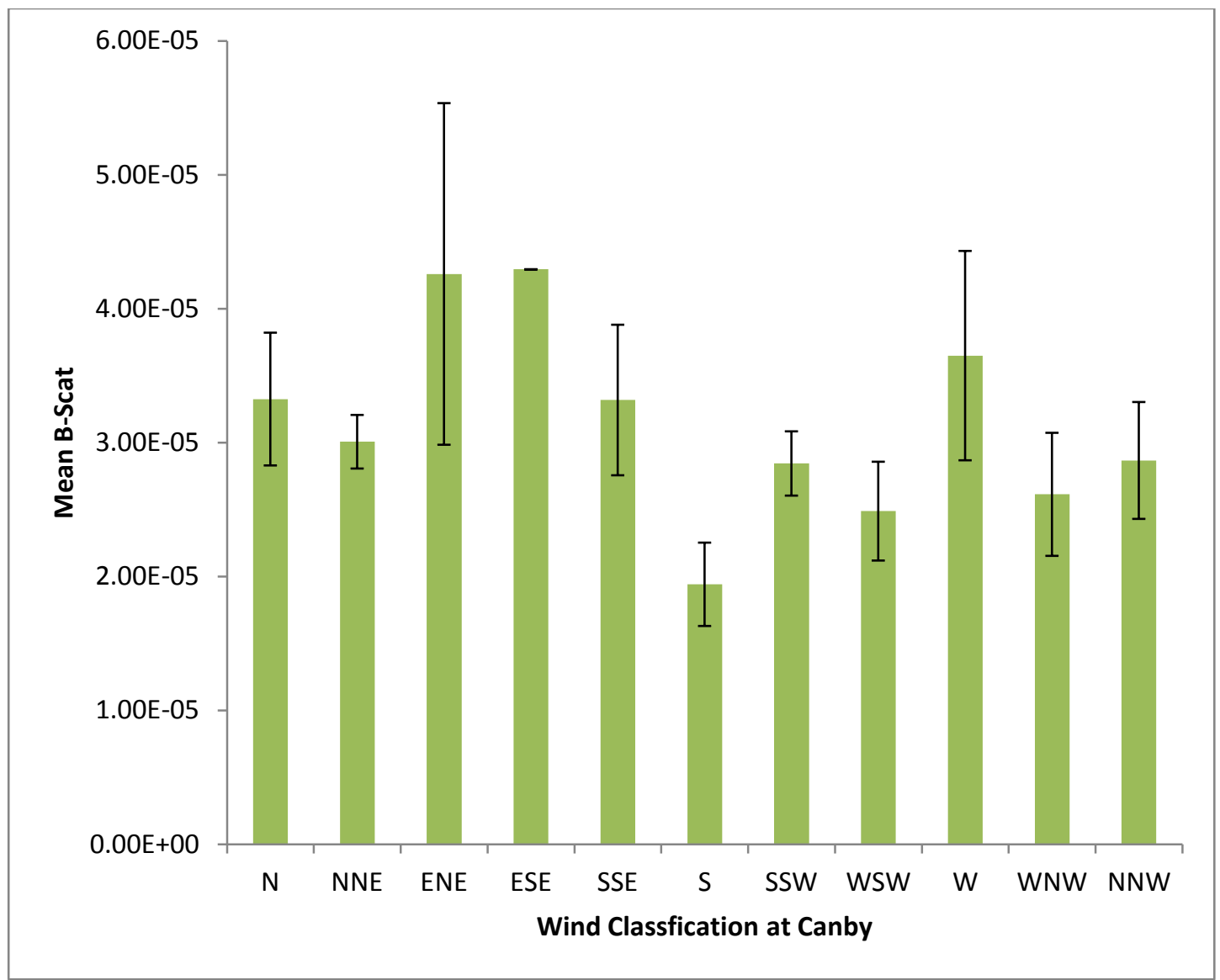

Figure 12 Average daily b-scat by wind classifications at the Canby site. Error bars indicate standard error.

The average daily b-scat at the Canby site is show in Figure 12. This shows quite a bit of variability in the amount and direction of b-scat. This may be highly influenced by its location in the center of an agricultural area. There is some higher b-scat when the wind comes from an easterly direction. 


\section{Wind Direction and Ozone}

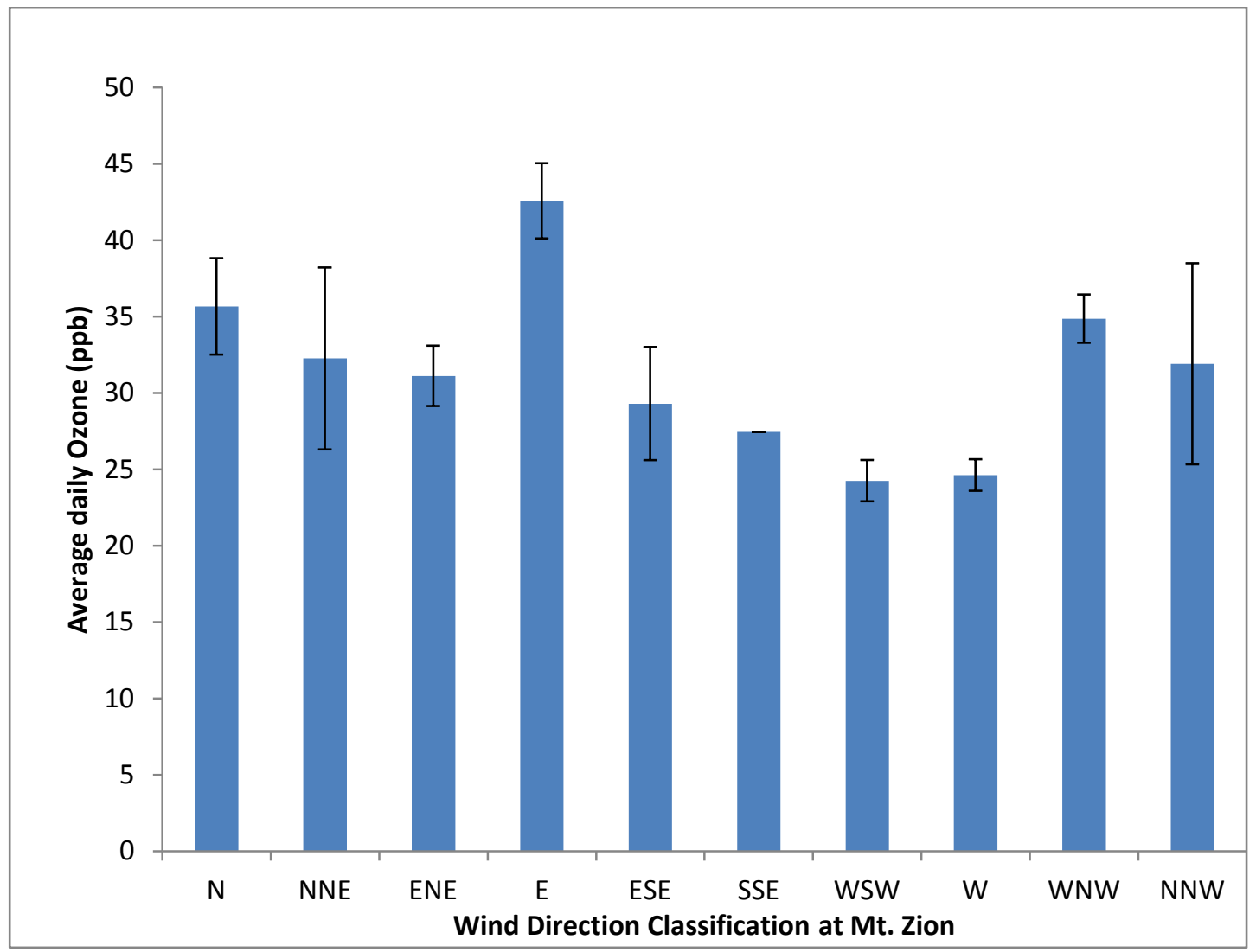

Figure 13 Average daily ozone concentrations by wind classifications at the Mt. Zion site. Error bars indicate standard error.

Mean ozone on days in summer sample days in 2010 and 2011 were classified in each of the 12 directions. Direction classifications were omitted if there were no days classified. Error bars are standard error. As can be seen in Error! Reference source not found., overall wind patterns varied greatly and the highest observed $\mathrm{O}_{3}$ concentrations are found in easterly wind flows. 
Table 6 Numerical Distribution of Ozone by wind direction at the Mt. Zion site

\begin{tabular}{|l|r|r|r|}
\hline Class & Mean Ozone & \multicolumn{1}{c|}{ St. Dev } & Sample Days \\
\hline N & 35.6712 & 7.7361 & 6 \\
\hline NNE & 32.2608 & 13.3128 & 5 \\
\hline ENE & 31.1234 & 11.1763 & 32 \\
\hline E & 42.5820 & 9.2191 & 14 \\
\hline ESE & 29.3082 & 9.0730 & 6 \\
\hline SSE & 27.4534 & & 1 \\
\hline WSW & 24.2600 & 4.2787 & 10 \\
\hline W & 24.6307 & 9.0018 & 76 \\
\hline WNW & 34.8676 & 9.7327 & 38 \\
\hline NNW & 31.9126 & 16.1247 & 6 \\
\hline
\end{tabular}

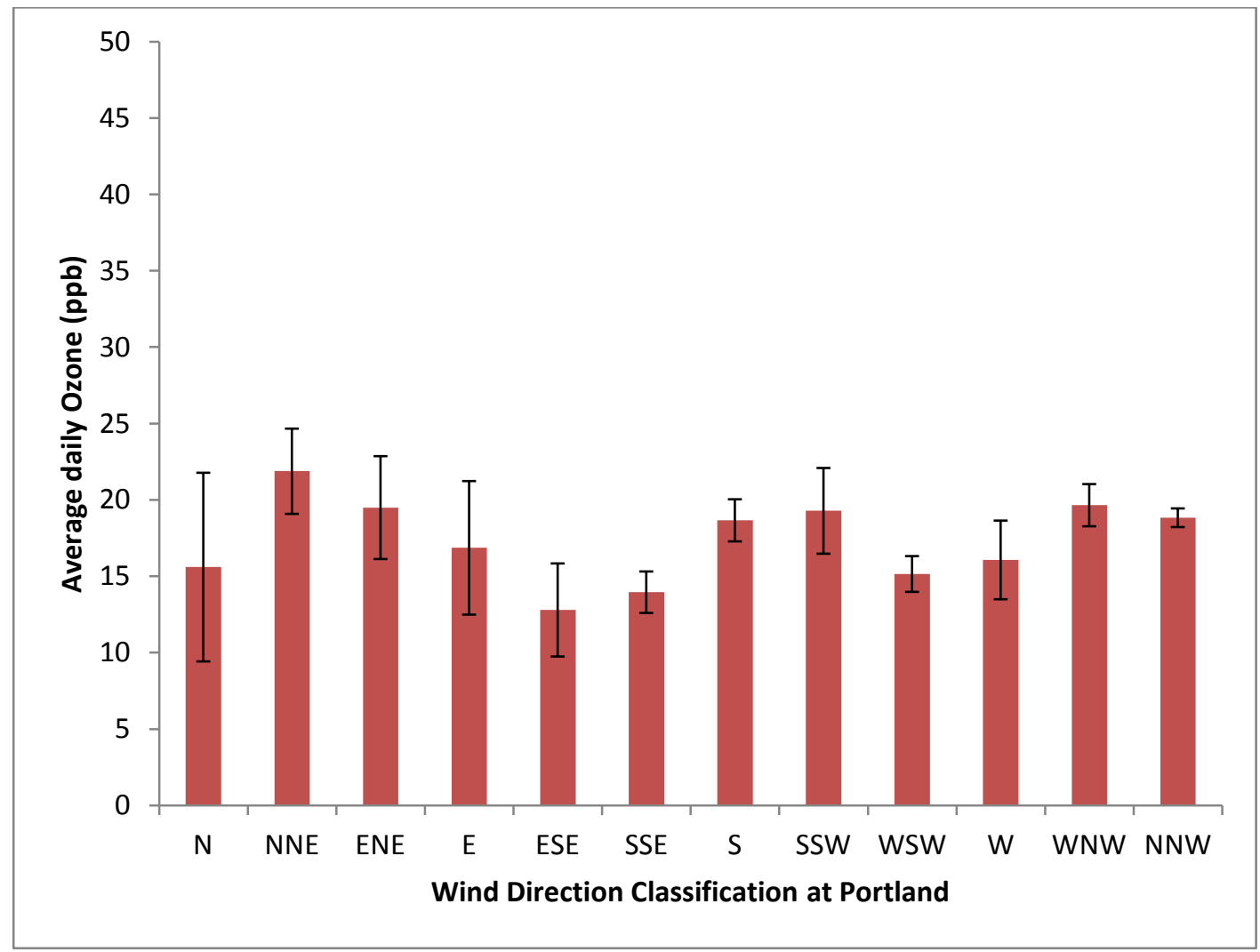

Figure 14 Average daily Ozone at the Portland Oregon site by wind classifications. Error bars indicate standard error.

Daily average ozone concentrations vary from around 12 to $22 \mathrm{ppb}$ at the Portland Oregon sampling site. This is shown in Figure 13. 


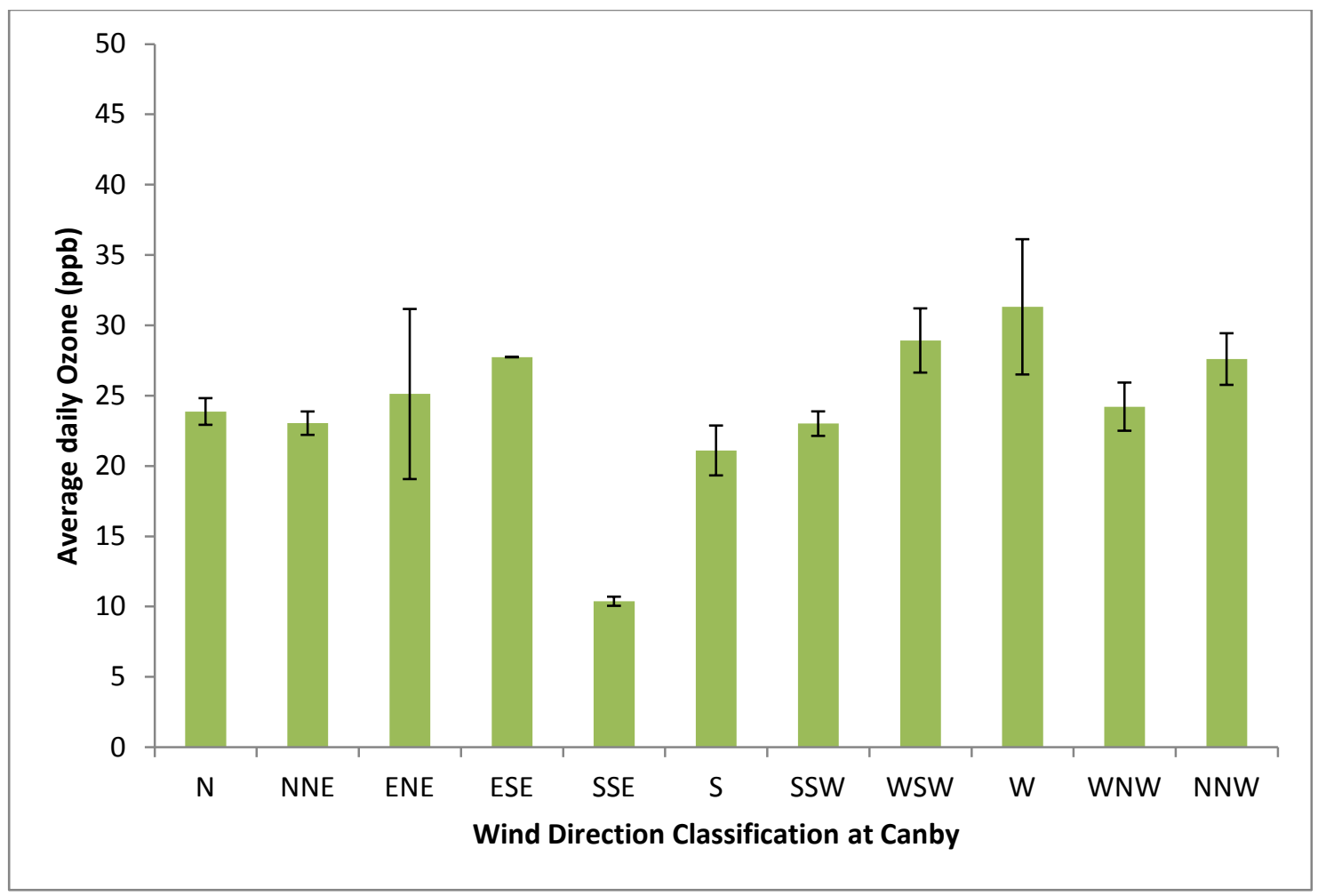

Figure 15 Ozone Concentrations by Wind Direction at Canby Oregon. Error bars indicate standard error.

In Figure 15, the ozone concentrations at Canby Oregon seem to be at a consistent concentration no matter where the wind direction is coming from. The wind from the south-south-east direction may be lower than the rest, however very few days were seen with that overall wind direction.

\section{Correlations with ambient gas-phase species}

The concentrations of average daily ozone at Mt. Zion and the Portland site were averaged by 24 hour periods and then grouped by wind direction. The correlation was greater on days when the wind blew from the west into the gorge than on days when the wind came from the east. 


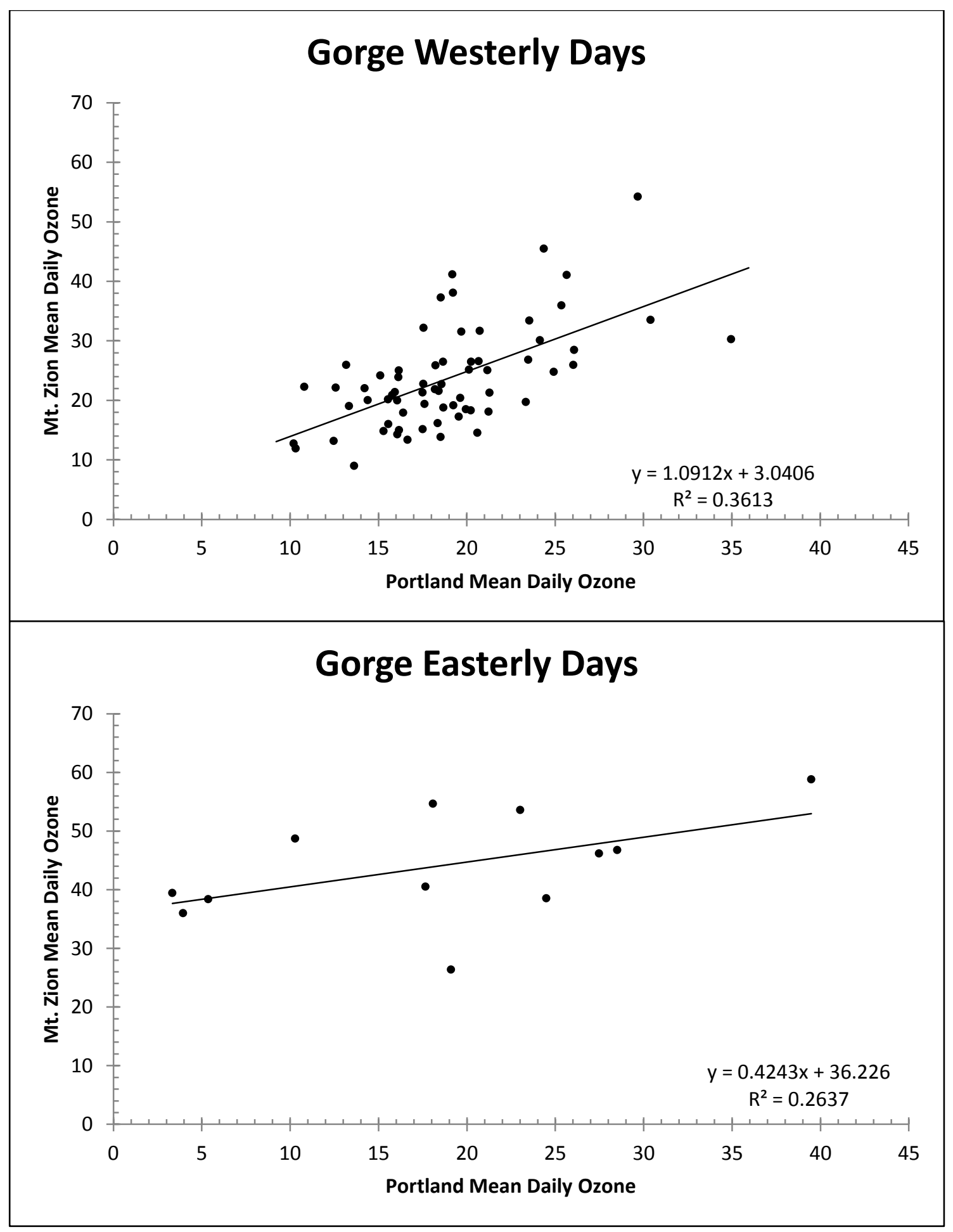

Figure 16 The correlation between Ozone concentrations in Portland and Mt. Zion and wind direction in the Gorge 


\section{Relationships between Filter Organic Nitrates and Ambient Data}

The data from the filters was aggregated by filter day. Filter days were considered to span from 7am when the filter was started to 7 am the next day. There was one date where the organic nitrate concentration was significantly higher than other dates: on September 12, 2011, the organic nitrates integrated peak area was 5.656 at the Reed Site compared to typical values of less than 3.0. The average temperature the prior day was $93^{\circ} \mathrm{F}$, the day of sampling, $76^{\circ} \mathrm{F}$, and the next day was $70^{\circ} \mathrm{F}$. The wind roses show that the wind was coming from the north-north-west at Mt. Zion and was split between the north-north-west and the south at Portland. There were large fires outside of Goldendale Washington and Hood River Oregon that may have contributed to the abundance of organic nitrates along with the high temperatures.
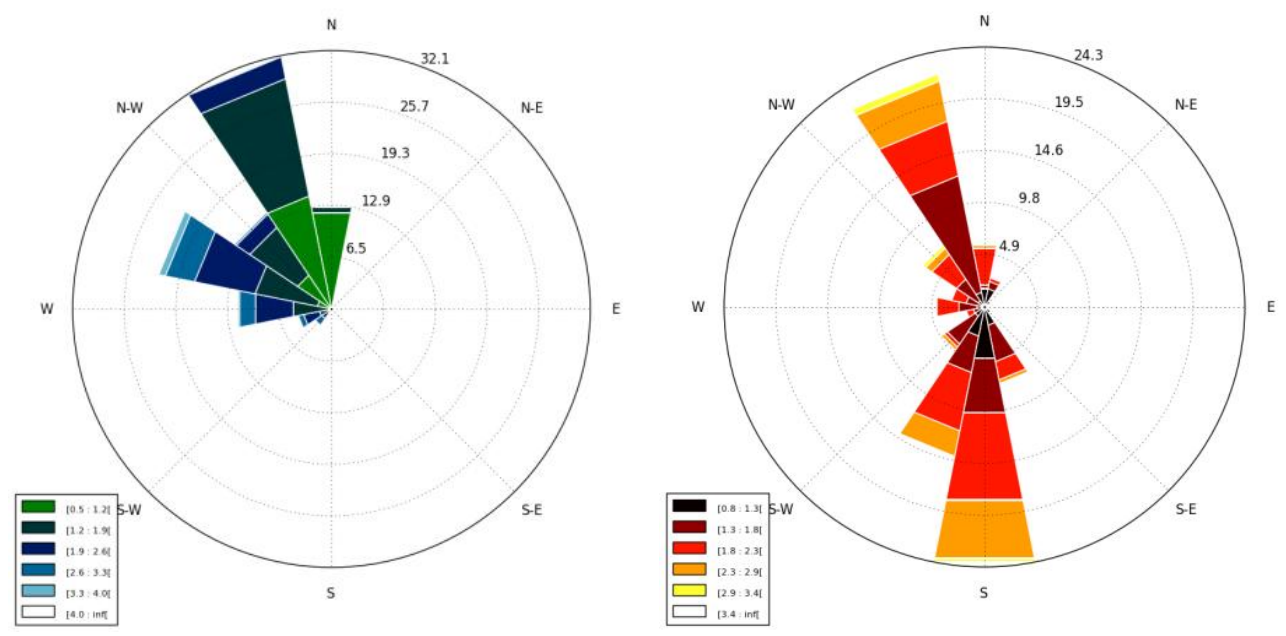

Figure 17 Wind Roses on September 12th, 2011. The blue wind rose represents wind at Mt. Zion, the Red at Portland 


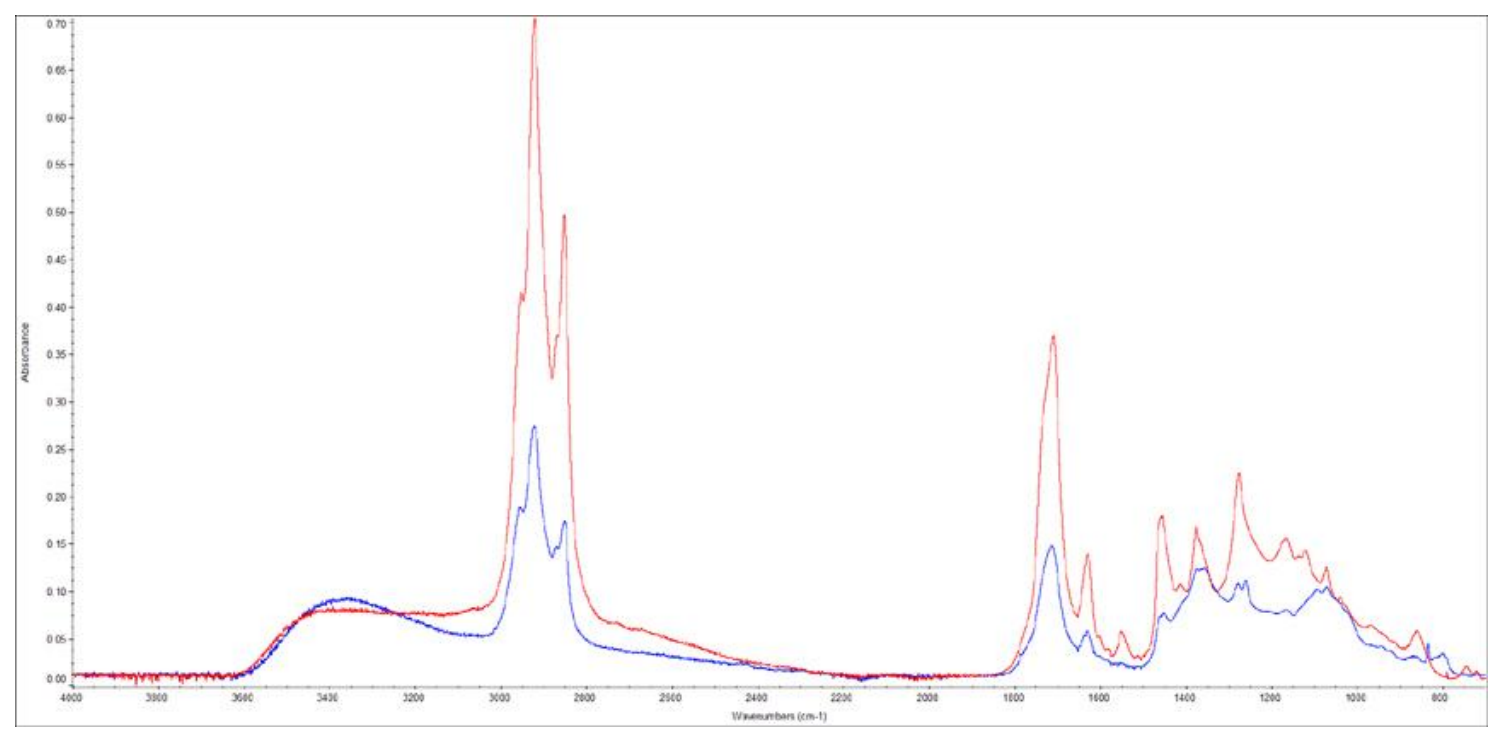

Figure 18 Spectra showing the September 12th filter. The Reed filter is shown in red, the Mt. Zion filter is shown in blue.

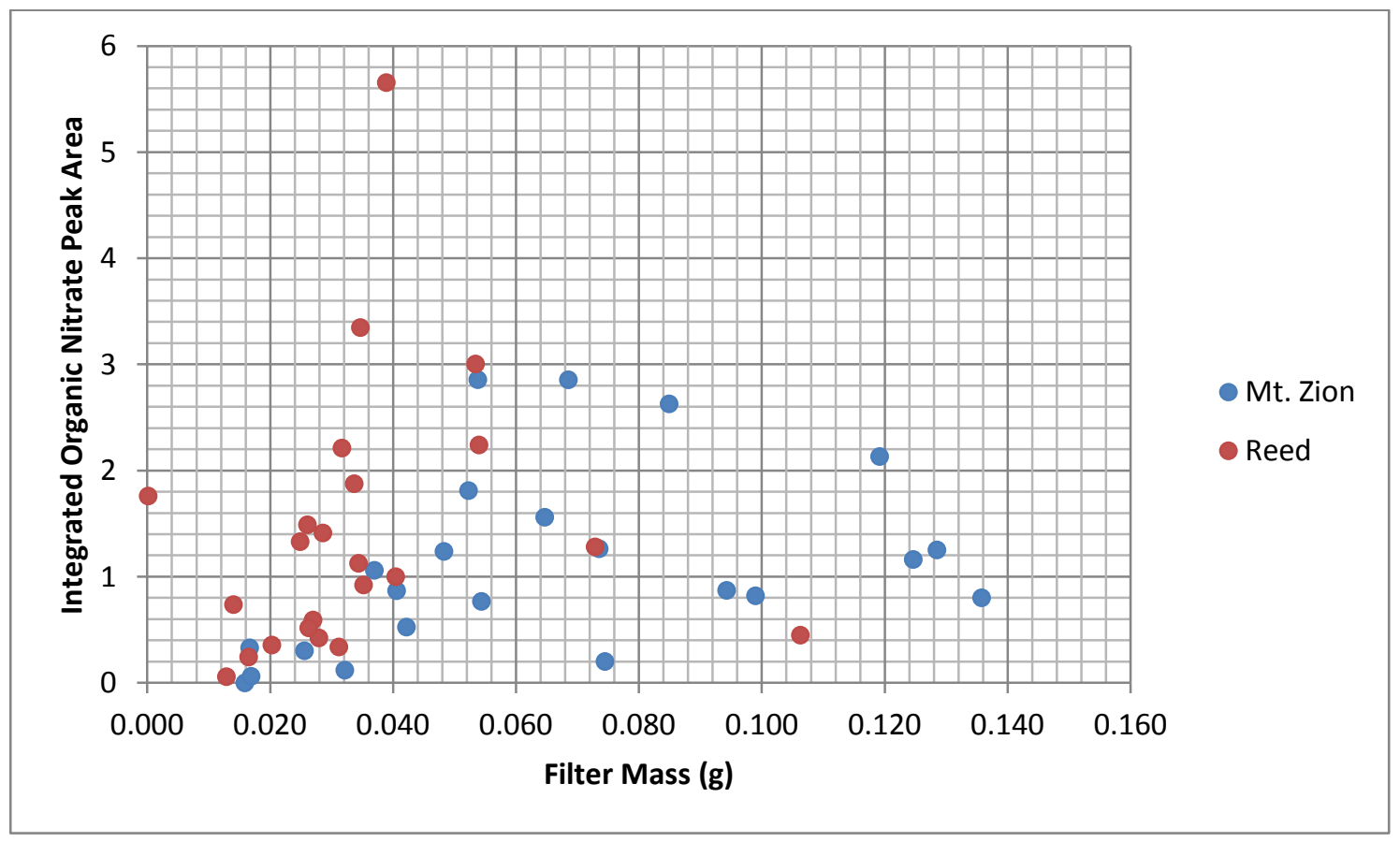

Figure 19 Relationship between observed organic nitrate and filter mass. 
The relationship between organic nitrate peak area and filter collected mass is not very strong (see Figure 19). There is however a more significant relationship between the filters collected at Mt. Zion and mass than those from Reed College. The filters ran at Reed college tend to have much less weight than the filters ran at Mt. Zion. The filters collected at Mt. Zion also looked darker and had more of a dusty appearance than the filters ran at Reed, suggesting additional contribution from inorganic dust aerosol that would not be extracted by organic workup.

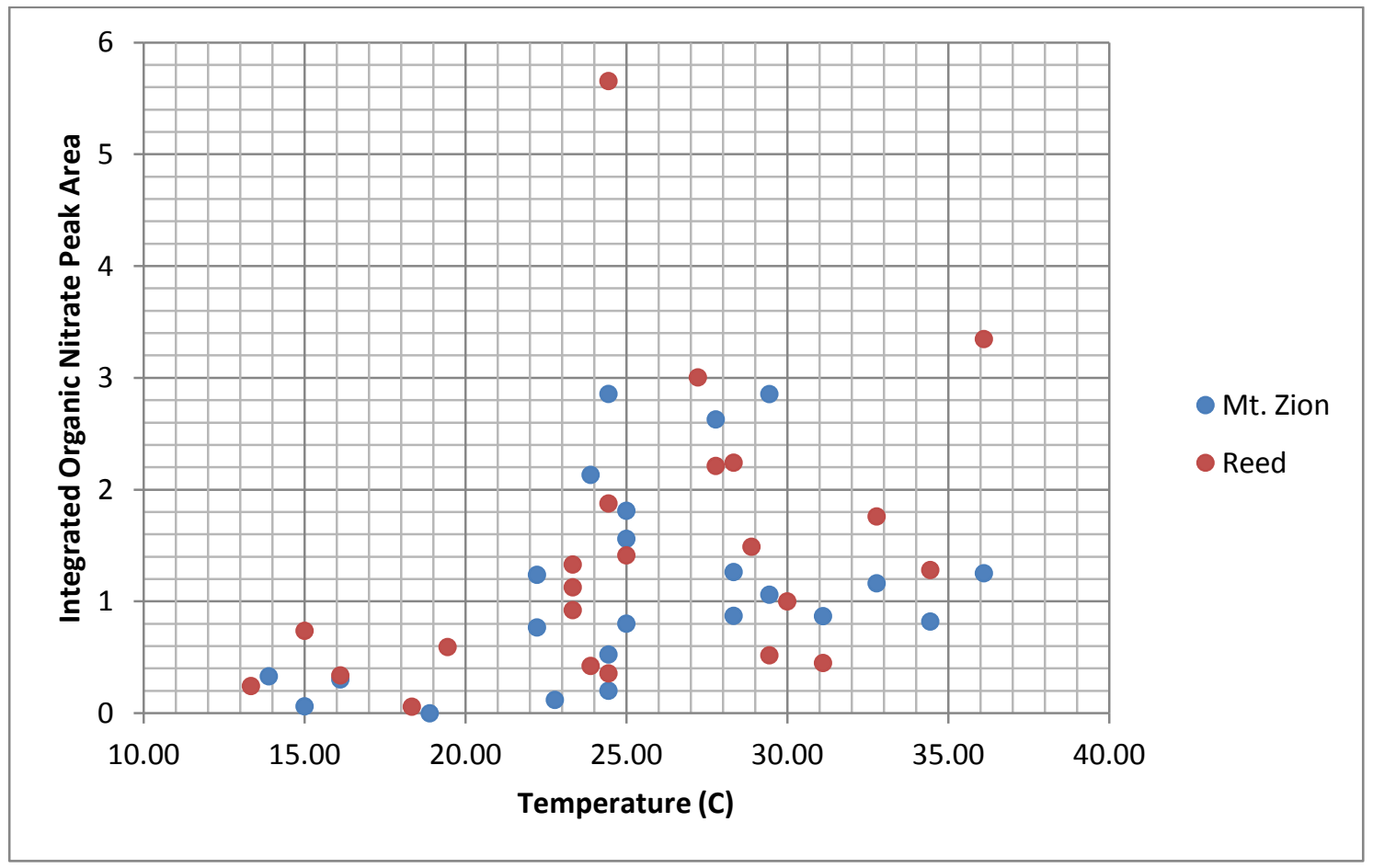

Figure $\mathbf{2 0}$ Correlation between both observed organic nitrate and temperature.

The relationships between measured organic nitrates and the temperature at both sites are very similar. This shows that temperature has a consistent effect on the production of nitrate at either site. 


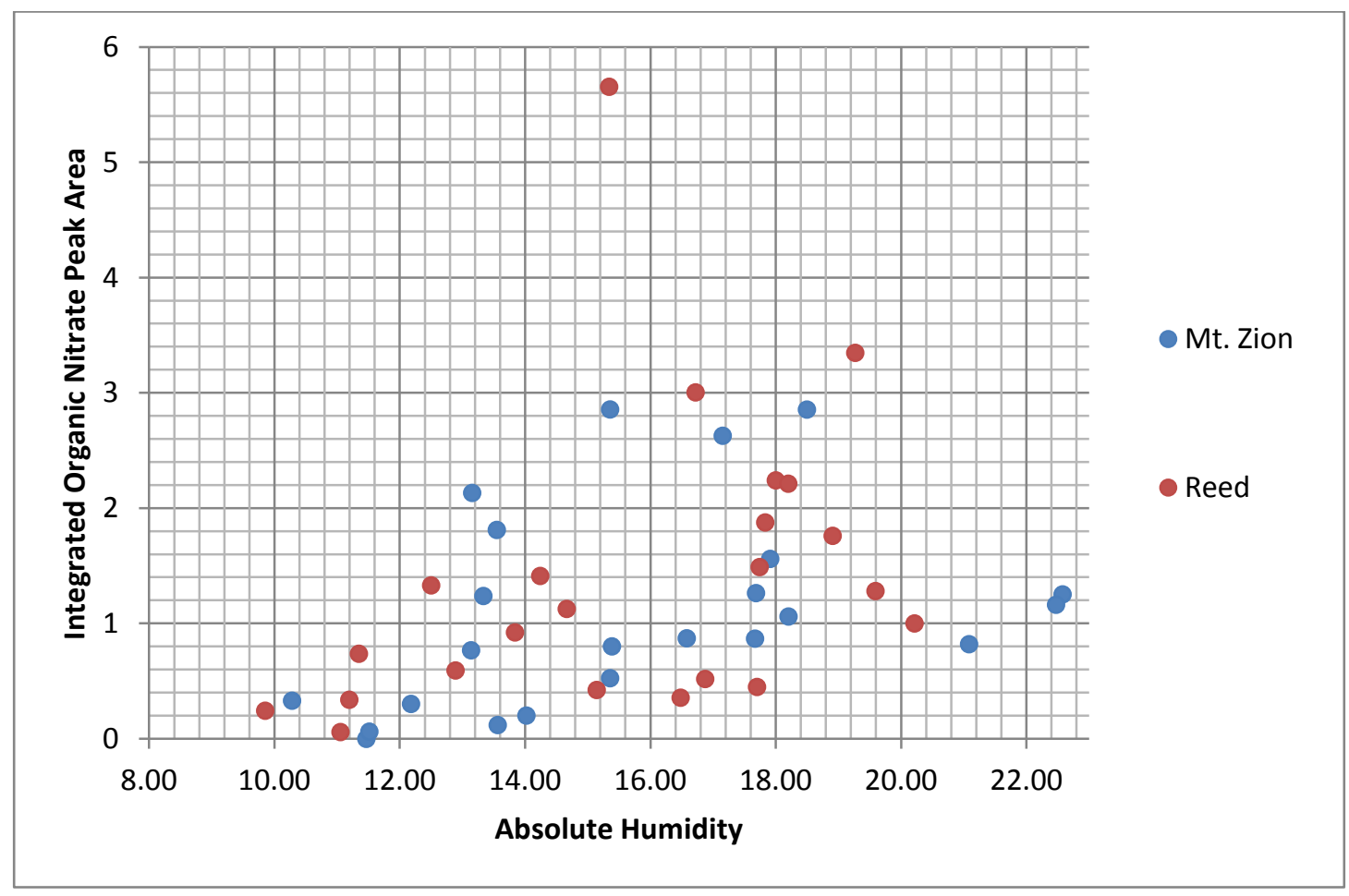

Figure 21 Relationship between absolute humidity and observed organic nitrates in the field.

The relationships between absolute humidity and organic nitrates on the filers also showed little difference between sites. Absolute Humidity was calculated using Relative Humidity and Temperature. This was done to remove any chemical reaction connection due to temperature and look only at the relationship between water and the formation of the organic nitrates. 


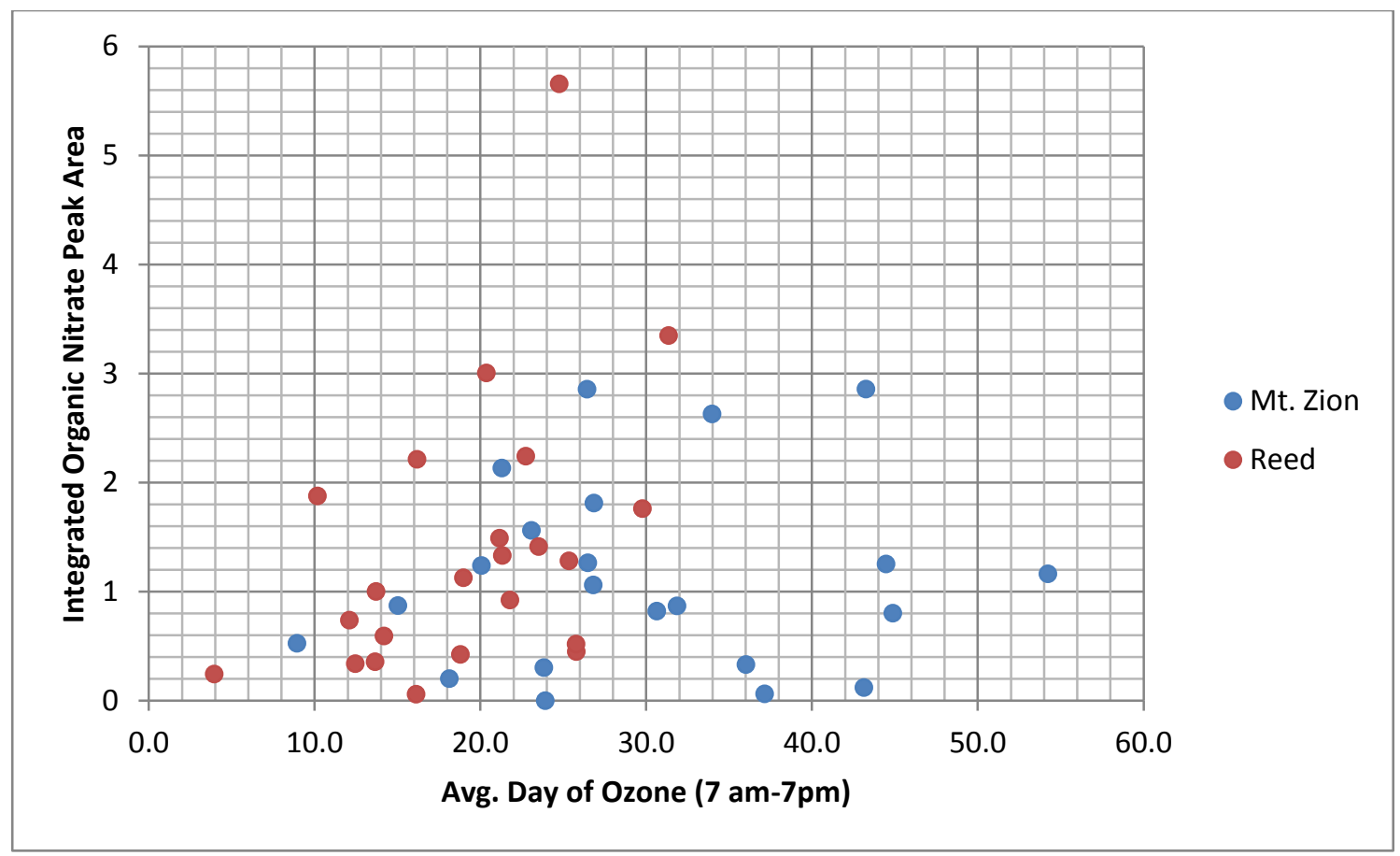

Figure 22 Relationship between the day of sampling ozone and the observed organic nitrate in the field.

The average ozone during the day appears more strongly correlated $\left(R^{2}=0.189\right)$ with the amount of organic nitrate production in Portland than at Mt. Zion $\left(R^{2}=0.007\right)$. This suggests that while the ozone formed during the day at Reed is available to form the Nitrate radicals at night which then leads to formation of the organic nitrates aerosols that we can sample on our filters, the amount of ozone seen at Mt. Zion has little influence on the production of nitrate radicals. 


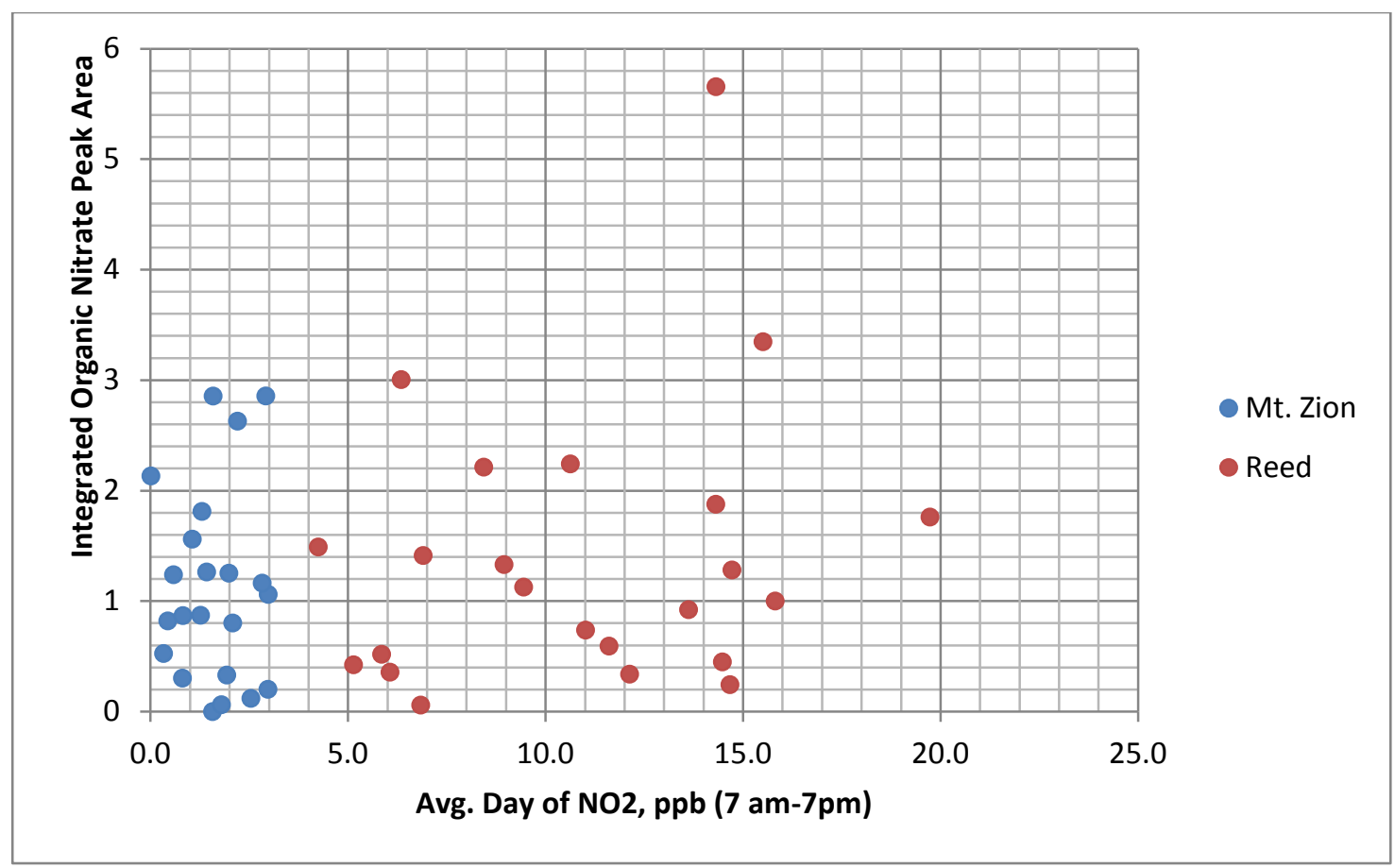

Figure 23 The relationship between day of NO2 and organic nitrates in the field has very little significance.

The relationship between the formation of the organic nitrate aerosol and day of $\mathrm{NO}_{2}$ is not significant $\left(R^{2}=0.000\right)$ at Mt. Zion. There may be some relationship $\left(R^{2}=0.047\right)$ at Reed, but it is very small. This suggests that the concentration of $\mathrm{NO}_{2}$ during the day has little effect on the formation of the nitrate radicals at night. 


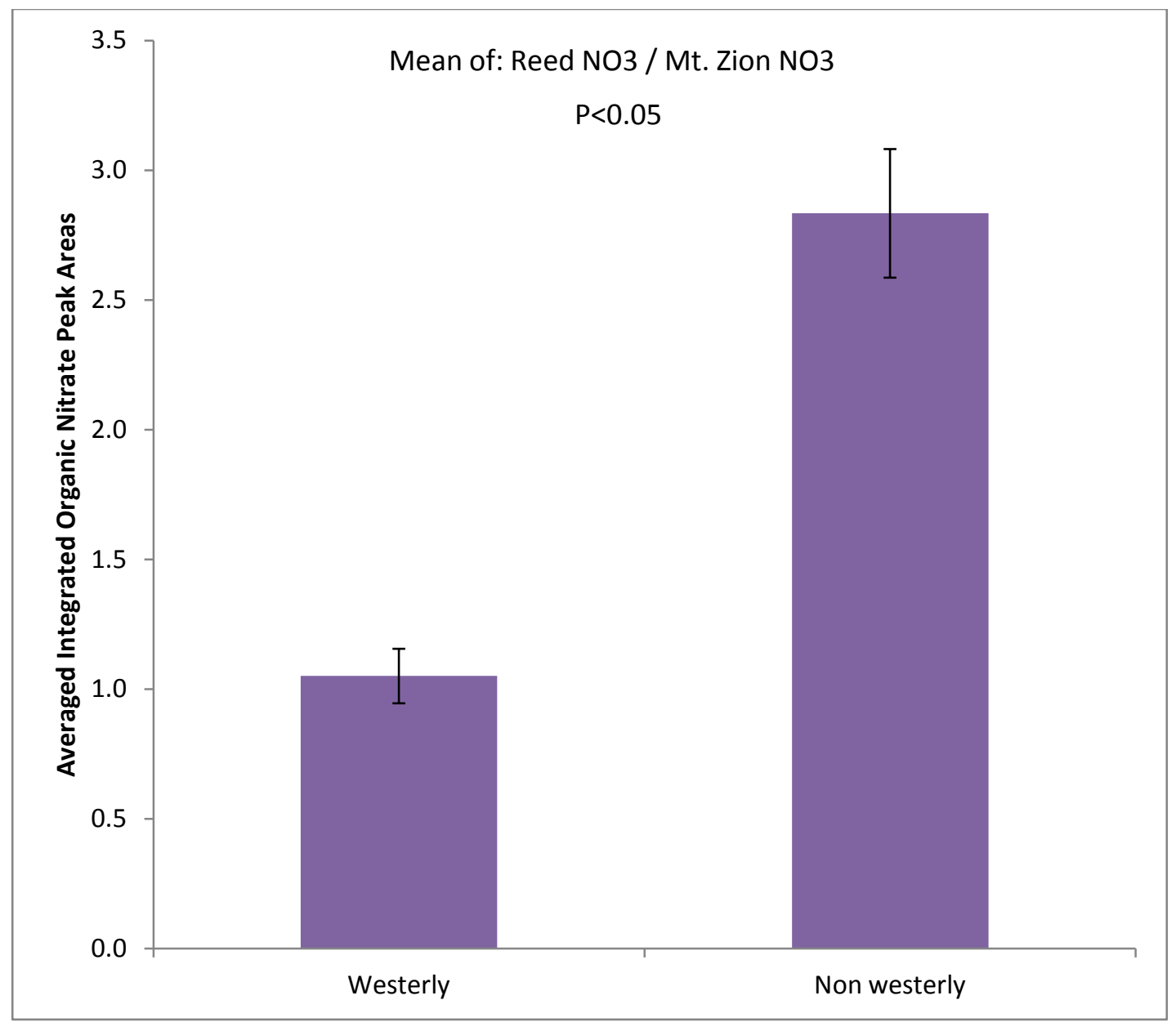

Figure 24 Ratios of observed organic nitrate concentration of $\mathrm{NO}_{3}$ at Reed and Mt.Zion on westerly and non westerly days. 


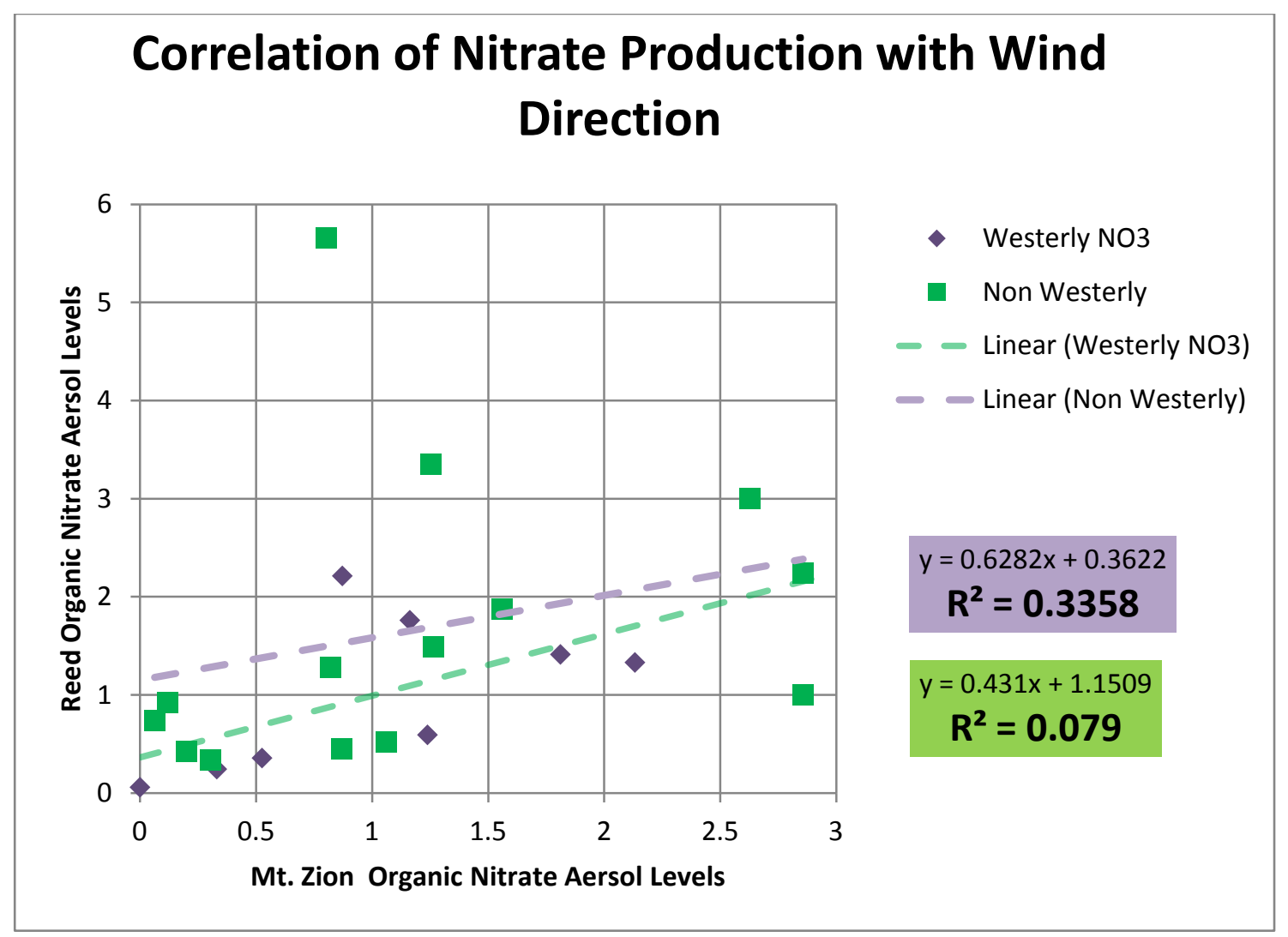

Figure $\mathbf{2 5}$ This chart is showing the correlation between observed organic nitrate levels and general wind direction.

Figure 24 shows the relationship between the wind direction and the formation of the organic nitrates using the Pearson's correlation. The ratio tells us that on days where the wind comes from a westerly direction the ratio of organic nitrate formation is much closer to one than on the days where the wind comes from another direction. This is demonstrating a close relationship on days with westerly wind in the gorge. On non-westerly days the concentration at Reed is three times higher than at the CRG site. Another way of looking at the relationship between nitrate production and wind 
direction, Figure 25 is showing that on days when the wind is coming from the west at Mt. Zion, the nitrate levels at Reed and Mt. Zion are more closely related.

\section{Production of the Organic Nitrate Radical}

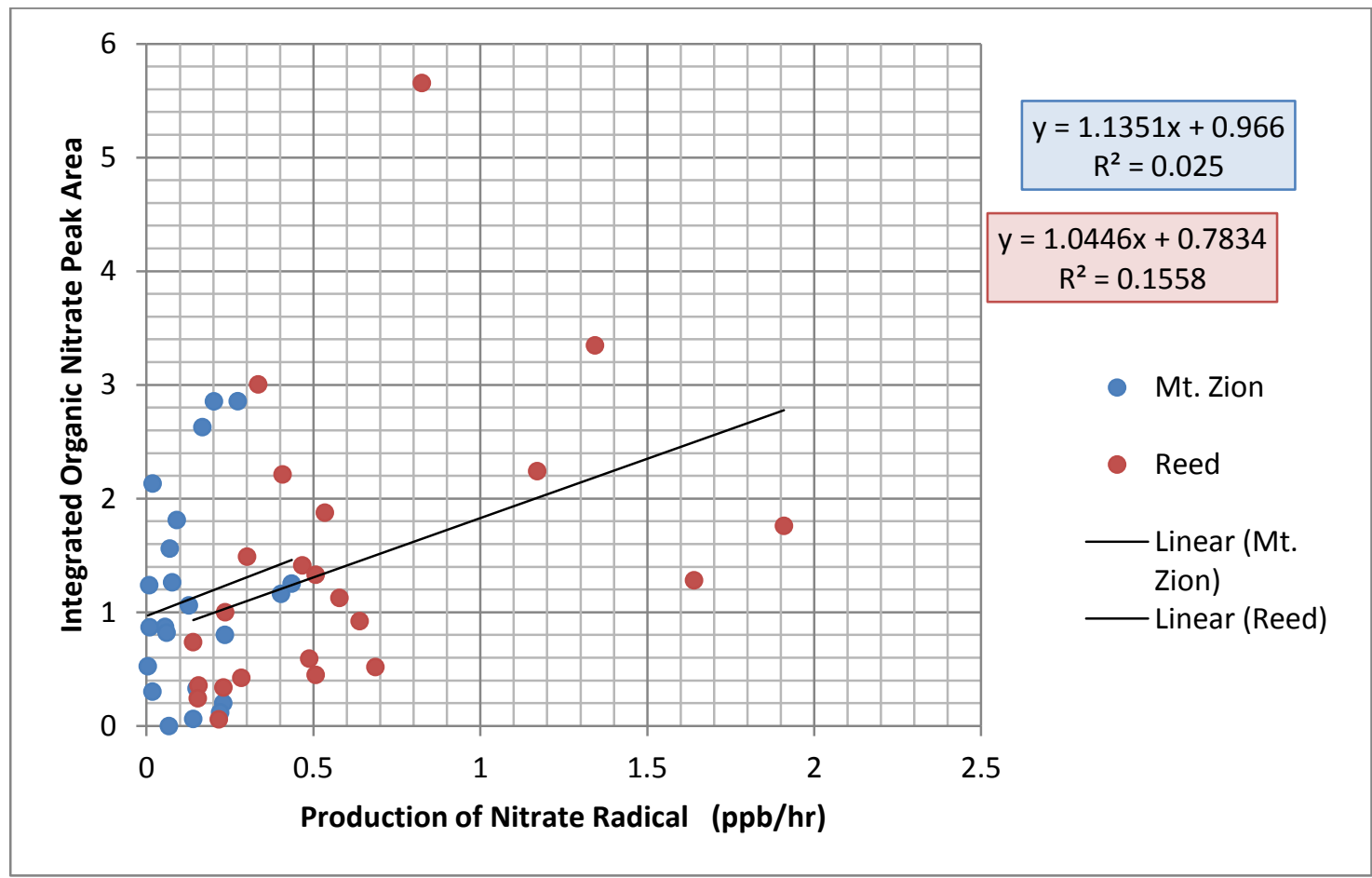

Figure 26 Relationship between observed aerosol organic nitrate and production of the nitrate radical, calculated from observed ambient $\mathrm{NO}_{2}$ and $\mathrm{O}_{3}$ concentrations (see text).

The predicted nitrate production was calculated from the concentrations of ozone and nitrogen dioxide during nighttime hours. Nighttime was defined as 7pm through 7 am. In Figure 26, the days with observed organic nitrates were correlated with the average nighttime production of the nitrate radical $\mathrm{NO}_{3}$. This figure includes all filter dates. In Figure 27, the observed organic nitrates were correlated with $\mathrm{NO}_{3}$, but 
the days when temperature was over $30^{\circ} \mathrm{C}$ were removed. The correlations in Portland were much stronger when the high temperature was removed. 


\section{Mt. Zion}
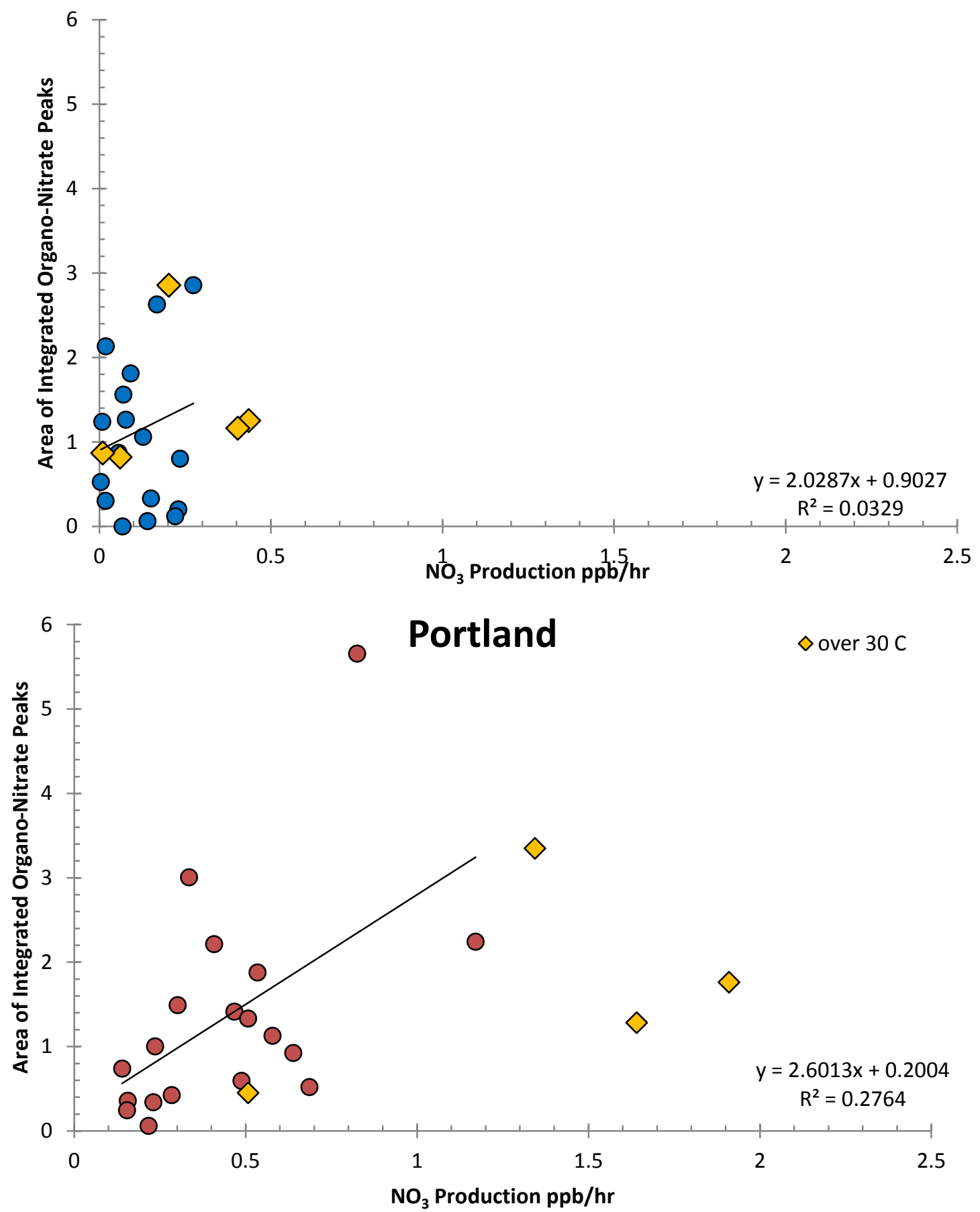

Figure 27: Levels of organic nitrate are much more strongly correlated with NO3 production in Portland. Diamonds indicate very hot days (mean temperature $>30^{\circ} \mathrm{C}$ ) 


\section{Discussion}

\section{Wind Direction Patterns and Pollutants}

This study looked at the affect that wind direction would have on the pollutants coming out of the Portland metropolitan region. Wind direction during the summers of 2010 and 2011 varied by each sampling site. The observations mirror wind patterns seen in previous studies done in the CRG (Green, 2009). At the Portland site, the predominant wind direction for both 2010 and 2011 was from the north-north-west direction. This means that the wind was blowing across highway 26 from the north towards the Portland site. At the Canby Oregon site, the wind was much more mixed. Wind often came from the north-north-east and the north. This would be moving pollution from Portland Oregon toward the Canby site. At the Mt. Zion site, the wind comes strongly from the west. In Figure 9, the wind at Mt. Zion has a predominantly westerly direction when wind is coming from the north-north-west in Portland. This shows a correlation between the two sites and specific wind directions. More specifically these data suggest an overall pattern of wind that would drive pollutants from the Portland Metro Area into the Columbia River Gorge during the summer months supporting previous findings from Green et al. (2008)

Wind direction has a strong influence on concentrations of b-scat in the Columbia River Gorge but the influence is less significant in Portland. The b-scat levels at Mt. Zion were much higher on days when the wind was classified as westerly (Figure 10). This would indicate transport of particulate matter pollution down the CRG. This is 
different than when wind comes from the east during the summer time. The b-scat is much lower overall. These conditions would match a flow tube effect of the particulate being pushed up gorge. In Portland, Figure 11 shows the b-scat overall has only a small amount of deviation. This is most likely due to the location of the sampling site between several large transportation arteries, including Powell Boulevard and I-205. These data would indicate, as expected, that pollutants found at Mt. Zion were primarily transported there while pollutants in Portland originated locally. Further, wind direction had an influence on particulate concentrations at the Canby site again indicating transported pollutants. Higher levels of b-scat were observed at this site, during days when the winds were from the easterly or westerly directions.

The levels of $\mathrm{O}_{3}$ in the CRG tell a much more complex story. $\mathrm{O}_{3}$ levels at Mt. Zion are highest when the wind is from the east and significantly lower when the wind is from the west. However, as shown in Figure 16, $\mathrm{O}_{3}$ levels in Portland and at Mt. Zion are much more strongly correlated when the wind is from the west. Together these data suggest that the pollutants from the eastern sources may produce higher concentrations of $\mathrm{O}_{3}$ at the Mt. Zion site which are decoupled from Portland pollution sources. This is a promising finding and may indicate that the CRG exhibits flow tube behavior in the easterly direction. Higher levels of $\mathrm{O}_{3}$ at $\mathrm{Mt}$. Zion would be consistent with that behavior, as $\mathrm{O}_{3}$ is a secondary pollutant and may be more prevalent in the older plume that would be reaching Mt. Zion from the Boardman coal plant in the east. 
However, with the currently available data it cannot be determined if these high $\mathrm{O}_{3}$ concentrations on easterly days are the result of plume age or a qualitative difference in the pollution sources. Canby, Oregon has higher $\mathrm{O}_{3}$ concentrations than Portland, which would be consistent with secondary pollutant formation in an aging plume.

Concentrations of $\mathrm{O}_{3}$ are similar when the wind blows from the north, east, and west. This could be due to urban pollution from Portland. There are lower concentrations of $\mathrm{O}_{3}$ when the wind blows up from the south and the south-south-east suggesting that pollutants in this area are from the Portland metro area.

Patterns of wind direction as well as levels of pollutants support potential flow tube behavior in the CRG. However, pollutant data from the Canby site exhibit some similarity with data from the Mt. Zion site suggesting that further research is required to demonstrate that the flow tube effect goes beyond simple downwind transport of pollutants. However higher levels of ozone at Mt. Zion on easterly days may be indicative of the flow tube behavior of the CRG limiting dilution effects as the plume ages.

\section{Organic Nitrates}

Little correlation was found between measured aerosol organic nitrate concentrations and individual oxidants involved in its production: $\mathrm{O}_{3}$ and $\mathrm{NO} 2$. The correlation between the measured organic nitrates and filter mass, was significantly greater at Mt. Zion than the correlation in Portland, and may have been greater on the 
coolest days of summer. However, this occurred on an insufficient number of days to make the correlation meaningful. Also, the Mt. Zion filters themselves had a dusty appearance which suggests the accumulation of dust and particulate may have been from agricultural productions and inorganic in nature.

The correlation between organic nitrates and temperature was strong and very similar at both sites. In Portland the $\mathrm{R}^{2}$ was equal to 0.143 , while at Mt. Zion the $\mathrm{R}^{2}$ was equal to 0.159 . This suggests that temperature does have an impact on the formation of organic nitrates with a similar mechanism at both sites. The correlation between organic nitrates and absolute humidity was also similar to the correlations found with temperature.

There was very little correlation between daily average day of ozone and organic nitrates peak area at Mt. Zion. There was a greater correlation however at the Portland site where $R^{2}$ was equal to 0.189 . This is related to the fact that while the organic nitrate concentrations were close in amount, the concentrations of average ozone and $\mathrm{NO}_{2}$ were different at the two sites. There was little correlation between average day of $\mathrm{NO}_{2}$ and organic nitrates found on the sampled filters. The concentration of $\mathrm{NO}_{2}$ was very small at Mt. Zion. These two pollutants are one pathway to create the nitrate radical, which is used to make organic nitrates.

Correlations between aerosol organic nitrate concentrations in Portland and Mt. Zion were much stronger during periods of westerly wind (Figure 24 and Figure 25). 
Further, during periods of westerly wind, the concentration of organic nitrate levels are very similar at both sites. This suggests that some part of the organic nitrate production cycle is being influenced by the flow tube effect in the CRG. Because the $\mathrm{NO}_{2}$ is so low at Mt. Zion and significantly higher in Portland while the organic nitrate levels are similar at both sites it seems likely that these secondary pollutants are being produced while the plume is being pushed out into the CRG.

\section{Organic Nitrates and the Production of the Nitrate Radical}

This study assumed that the production of the $\mathrm{NO}_{3}$ radical is a rate limiting step for organic nitrate formation. A correlation was observed between organic nitrate aersol and the calculated production rate of organic nitrate radicals. This is consistent with a $\mathrm{NO}_{3}$ initiated source of organic nitrates; neither $\mathrm{O}_{3}$ nor $\mathrm{NO}_{2}$ individually predict organic nitrate production, but their multiplicative product is more strongly correlated with observed aerosol organic nitrate. In Figure 26, the correlation between production of $\mathrm{NO}_{3}$ in Portland and actual formation of organic nitrates was $\mathrm{R}^{2}=0.155$. The Reed production point at 5.656 is considered an outlier. Its production is significantly above that of any other point. The wind patterns on that date, September $12^{\text {th }}, 2011$ have a north-west direction at Mt. Zion. In Portland it has a split between north-north-west and south. The previous day has significant high temperatures, but the day of sampling was an average $76^{\circ} \mathrm{F}$. There were several large fires in Oregon and Washington that week that were impacted by the high temperatures, which could have led to a large increase 
in the organic nitrate production. The filter for September $12^{\text {th }}$ at Reed also shows a large amount of alkane functional groups that could have been created from the products of the near-by wildfires.

When temperature is incorporated with the analysis of aerosol organic nitrate and $\mathrm{NO}_{3}$ radical correlations, two interesting slopes emerge. After temperatures over $30^{\circ} \mathrm{C}$ were removed, the correlation between organic-nitrates and $\mathrm{NO}_{3}$ production increased to $\mathrm{R}^{2}=0.276$ at Portland. The correlation at Mt. Zion remained low. High temperatures may lead to increased $\mathrm{NO}_{3}$ but not necessarily organic nitrates. The effect of temperature on organic nitrate production may be small, but it is similar at both sites. Temperature can have a large effect on isoprene production, which increases with temperatures to $35^{\circ} \mathrm{C}$ (Singaas 2000). At temperatures above $35-40^{\circ} \mathrm{C}$, isoprene production can be reduced. Similar trends are expected with other biogenic VOC's. Since there is significant scatter in the correlation of the aerosol organic nitrate with $\mathrm{NO}_{3}$, this suggests a role of varying $\mathrm{BVOC}$ as a reactant controlling the production of organic nitrates. This would be consistent with the temperature dependences observed, since higher emission rates are expected at higher temperatures, thus resulting in higher surface concentrations of BVOC. 


\section{Conclusion}

Pollution from human activities can be a significant part of humanity's interactions with the environment. Air pollution from transportation has a great impact on recreational use, economical, and human health. Transportation plays a large and ever increasing role in our society. Understanding the impacts of the pollution that arises from transportation is vital. Understanding the impact of pollution from the metropolitan region of Portland Oregon and its effect on the Columbia River Gorge could lead to better pollution controls and mitigation efforts.

This study did a chemical analysis along with a statistical analysis of air quality conditions in both Portland Oregon and the Columbia River Gorge. The chemical analysis was the extraction and analysis by FTIR for organic nitrates. This information was aggregated along with the ambient air quality measurements to look for correlations between production of the nitrate radical and the formation of organic nitrates.

The data shows that wind direction had an influence on the concentrations of ozone and b-scat seen at Mt. Zion and Portland Oregon. When organic aerosols were measured at Mt. Zion and Portland, correlations between absolute humidity, temperature and mass were significant. Little correlation was found between the aersol organic nitrates with ozone and $\mathrm{NO}_{2}$. However, greater correlation was observed between the aerosol organic nitrates and calculated production of the $\mathrm{NO}_{3}$ radical from $\mathrm{NO}_{2}$ and $\mathrm{O}_{3}$. The temperature dependence of aerosol organic nitrate concentrations 
could suggest a role for BVOCs in controlling organic nitrate production in addition to $\mathrm{NO}_{3}$ radical production.

This information can be used as a foundation for future work in the Columbia River Gorge. The data also supports a flow tube effect which may play into future mitigation techniques. This information is vital for how pollution is treated and reduced and its effect on human and ecological health. 


\section{References:}

A.W. Rollins, A. K.-S., J. Fry, T. Brauers, S.S. Brown, H-P. Dorn, W.P. Dube, H. Fuchs, A, Mensah, T.F> Mentel, F. Rohrer, R. Tillmann, R. Wegener, P.J. Wooldridge, R.C.Cohen (2009). "Isoprene oxidation and secondary organic aersol yields." Atmospheric Chemistry and Physics 9: 88578902.

Agency, E. P. (2008). Risk and Exposure Assesment to Support the Review of the NO2 Primary National Ambient Air Quality Standard. O. o. A. Q. P. a. Standards.

Agency, E. P. (2010). "Nitrogen Oxides." Retrieved June 1, 2010, 2010, from www.epa.gov/nitrogenoxides.

Agency, U. E. P. (2010). "FACT SHEET: FINAL REVISIONS TO THE NATIONAL AMBIENT AIR QUALITY STANDARDS FOR NITROGEN DIOXIDE." Retrieved May 30, 2010, 2010, from http://www.epa.gov/air/nitrogenoxides/pdfs/20100122fs.pdf.

Agency, U. S. E. P. (2010). "Ozone Information." Retrieved June 2, 2010, 2010, from http://www.epa.gov/ozone/.

Aiken, A. C. e. a. (2008). "O/C and OM/OC Ratios of Primary, Secondary, and Ambient Organic Aerosols with High-Resolution Time-of-Flight Aerosol Mass Spectrometry." Environmental Science and Technology 42(12): 4478-4485.

Allen, D. T., Paulen, Edward, J., Haimov, Mitchel I., Hering, Susanne V., Young, James R. (1994). "Fourier transform Infrared Spectroscopy of Aerosol collected in a low pressure impactor:Method development and field calibration." Aerosol Science and Technology 21(4): 325-342.

Anisworth, E., Yendrek, Craig, Sitch, Stephen, Collins, William, and Lisa Emberson (2012). "The Effects of Tropospheric Ozone on net Primary Productivity and Implications for Climate Change." Annual review of Plant Biology 63: 637-661.

Atkinson, R. (1990). "Gas-Phase Troposheric Chemistry of Organic Compounds: A review." Athmospheric Environment 24A(1): 1-41.

Barnack, A. (2011). 2011 Oregon Annual Ambient Air Monitoring Network Plan. A. Quality, Oregon Department of Environmental Quality. 
Berman, J. D., Fann N, Holliingsworth JW, Pinkerton KE, Rom WN, Szema AM, Breysse PN, White RH, Currieri FC (2012). "Health Benefits from Large-Scale Ozone Reduction in the United States." Environmental Health Perspectives.

Brauer Michael, A. M., Burnett Rick, Cohen Aaron, Dentener Frank, Ezzati Majid, Henderson Sarah, Krzyanowski Michal, Martin Randall, Van Dingenen Rita, van Donkelaar Aaron, Thurston George (2012). "Exposure Assessment for Estimation of the Global Burdan of Disease Attributable to Outdoor Air Pollution." Environmental Science \& Technology 46: 652-660.

Buller-McDonald, E., Allen, David, Brown, Nancy, Jacob, Daniel, Jaffe, Daniel, Kolb, Charles, Lefohn, Allen, Oltmans, Samuel, Parrish, David, Yarwood, Greg, Zhang Lin (2011). "Establishing Policy Relevant Background (PRB) Ozone Concentrations in the united States." Environmental Science \& Technology 45: 9484-9497.

Charron, A., Harrison, Roy M. (2003). "Primary particle formation from vehical emissions during exhaust dilution in the roadside atmosphere." Athmospheric Environment 37: 4109-4119.

Chen, C., Zhao Bin, Weschler Charles (2012). "Assesing the Influence on Indoor Exposure to "Outdoor Ozone" on the relationship between Ozone and short-term Mortality in U.S. Communities." Environmental Health Perspectives 120(2): 235-240.

Colvile, R. N., E.J. Hutchinson, J.S. Mindell, R.F. Warren (2001). "The transport sector as a source of air pollution " Atmospheric Environment 35: 1537-1565.

Cooper, S. M. P., D.L. (2000). "Spatial Distribution of tropospheric oozone in western Washington, USA." Environmental Pollution 107: 339-347.

Coury, C., Dillner Ann. (2008). "A method to quantify organic functional groups and inorganic compoinds in ambient aerosols unsing attenuated total reflectance FTIR spectroscopy and multivariate chemometric techniques." Atmospheric Environment 42: 5923-5932.

Coury, C., Dillner Ann. (2009). "ATR-FTIR charaterization of organic functional groups and inorganic ions in ambient aerosols at a rural site." Atmospheric Environment 43: 940-948.

Day, D., Lui Shang, Russell Lynn M, Ziemann Paul (2010). "Organonitrate group concentrations in submircon particles with high nitrate and organic fractions in coastal southern California." Atmospheric Environment 44: 1970-1979. 
Ebi, K., McGregor Glenn (2008). "Climate Change, Tropospheric Ozone and Particulate Matter, and Health Impacts." Environmental Health Perspectives 116(11): 1449-1455.

Fenn, M. E., Allen, S.B., Weiss, S., Jovan, L.H., Geiser, L.H., Tonnesen, G.S. , Johnson, R.F., Rao, L.E., Gimeno, B.S., Yuan, F., Meixner, T., Bytnerowicz, A. (2010). "Nitrogen criticals loads and management alternatives for $\mathrm{N}$-impacted ecosystems in California." Journal of Environmental Management 91: 2402-2423.

Fenn, M. E., Geiser, L., Bachman, R., Blubaugh T.J., Bytherowicz A. (2007). "Atmospheric depostion inputs and effects on lichen chemistry and indicator spieces in the Columbia River Gorge." Environmental Pollution 146: 77-91.

Fenn, M. E., Haeuber, Richard, Tonnesen, Gail, Baron, Jill, Grossman-Clarke, Susanne, Hope, Diane, Jaffe, Daniel, Copeland, Scott, Geiser, Linda, Rueth, Heather, and James Sickman (2003). "Nitrogen Emissions, Deposition and Monitoring in the Western United States "BioScience 53(4): 391-402.

Fry, J. L. A. K.-S., A.W. Rollins, P.J. Woolridge, S.S, Brown, H Fucchs, W. Dube, A. Mensah, M. dal Maso, R. Tillmann, H.-P. Dorn, T. Brauers, and R. C. Cohen (2009). "Organic nitrate and secondary aerosol yield from $\mathrm{NO} 3$ oxidation of beta-pinene evalluatedusing a gas-phase kinetics/aersol partitioning model." Atmospheric Chemistry and Physics 9: 1431-1449.

Gaffney, J. S., Nancy A. Marley (2009). " The impacts of combustion emissions on air quality and climate-From coal to biofuels and beyond. ." Atmospheric Environment 43: 23-36.

Green, M., Pitchford Marc, Morris Ralph, Norville Kent (2001). Columbia River Gorge Visibility and Air Quality Study: Knowledge and Additional Recommended Scientific Assesment to Consider.

Green, M., Xu Jin (2007). "Causes of Haze in the Columbia River Gorge." Journal of Air and Waste Management Association 57: 947-958.

Green, M., Xu Jin, Adhikari Narendra (2008). "Transport of Atmospheric Aerosol by Gap Winds in the Columbia River Gorge." American Meterological Society 47: 15-26. 
Grice, S., John Stedman, Andrew Kent, Melanie Hobson, John Norris, John Abbott, Sally Cooke (2009). "Recent trends and projections of primary NO2 emissions in Europe." Atmospheric Environment 43: 2154-2167.

Gruber, N., James N. Galloway. (2008). "An Earth-system perspective of the global nitrogen cycle." Nature 451: 293-296.

Hallquist, M., J.C. Wegner,, U. Baltensperger, Y. Rudich, D. Simpson, M. Claeys, J. Dommen, N.M. Danahue, C. George, A.H. Goldstien, J.F. Hamilton, H. Hermann, T. Hoffmann, Y. linuma, M. Jang, M.E. Jenkin, J.L. Sienfield, J.D> Surrat, R. Szmigielski, J. Wild (2009). "The formation , properties, and impact of secondary organic aerosol: current and emerging issues." Atmospheric Chemistry and Physics 9: 5155-5236.

Hewitt, C. N. (2001). "The atmospheric chemistry of sulphur and nitrogen in power station plumes." Atmospheric Environment 35: 1155-1170.

Jaffe, D. A. R., D.R. (2009). "Now you see it, now you don't: Impact of temporary closures of a coal-fired power plant on air quality in the Columbia river Gorge National Senic Area." Atmospheric Chemistry and Physics 9: 7997-8005.

Jones, A. M., Roy M. Harrison, J. Baker (2010). "The wind speed dependence of the concentrations of airborne particulate matter and NOx." Atmospheric Environment 44: 16821690.

latza, U. (2009). "Effects of Nitrogen dioxide on human health: Systematic review of experimental and epidemiological studies conducted between 2002 and 2006." International Journal of Hygiene and Environmental Health 212(3): 271-287.

Leisner, C., Ainsworth, Elizabeth (2012). "Quantifying the effects of ozone on plant reproductive growth and development." Global Change Biology 18: 606-616.

Linn, J. (2010). "The effect of cap-and-trade programs on firms' profits: Evidence from the Nitrogen Oxides Budget Trading Program." Journal of Environmental Economics and Management 59: 1-14.

Migliore, E. e. a. (2009). "Repiratory symptopms in childrem living near busy roads and their relationship to vehicular traffic:results of an Italian Multicenter study." Environmental Health 8(27): 1-16. 
Perraud, V., Bruns Emily, Ezell Michael J., Johnson Stanley N., Greaves John, Finlayson-Pitts Barbara (2010). "Identification of Organic Nitrtes in the NO3 Radical Initiates Oxidation of alphaPinene by Atmospheric Pressue Chemical Ionization Mass Spectrometry." Environmental Science \& Technology 44(15): 5887-5893.

Polidori, A., et. Al. (2008). "Organic PM2.5: Fractionation by Polarity, FTIR Spectroscopy, and OM/OC Ration for the Pittsburg Aerosol." Aerosol Science and Technology 42: 233-246.

Rice, A., Bostrom, Gregory (2011). "Measurements of carbon dioxide in an Oregon metropolitan region." Atmospheric Environment 45: 1138-1144.

Richter, A., John Burrows, Hendrick NuB, Claire Granier, Ulrike Niemeier (2005). "Increase in tropospheric nitrogen dioxide over China observed from space." Nature 437: 129-132.

Rollins, A. W., Smith Jared, Wilson Kevin, Cohen Ronald (2010). "Real Time In Situ Detection of Organic Nitrates in Atmospheric Aerosols." Environmental Science \& Technology 44(14): 5540 5545 .

Russell, L. M., Bahadur Ranjit, Ziemann Paul J. (2011). "Identifying organic aerosol sources by comparing functional group composition in chamber and atmospheric particles." PNAS 108(9): 3516-3521.

Sharp, J., Mass Clifford F. (2004). "Columbia Gorge Gap Winds: their climatological influence and synoptic evolution." Weather and Forcasting 19: 970-992.

Singaas, E. L., Sharkey T.D. (2000). "The effect of high temperature on isoprene synthesis in oak leaves." Plant, Cell and Environment 23: 751-757.

Tang, M. J. (2010). "Uptake of NO3 and N2O5 to Saharan dust, ambient urban aerosol and soot: a relative rate study." Atmospheric Chemistry and Physics 10: 2965-2974.

Tao, Y., Huang Wei, Huang Xialiang, Zhong Liuju, Lu Shou-En, Li Yu, Dai Lingzhen, Zhang Yuanhang, Zhu Tong (2012). "Estimated Acute Effects of Ambient Ozone and Nitrogen Dioxide on Mortality in the Pearl River Delta of Southern China." Environmental Health Perspectives 120(3): 393-398. 
Vallero, D. A. (2008). Fundamentals of Air Pollution, Elservier.

Vijayaraghavan, K. e. A. (2010). "A Case Study of the Relative Effects of Power Plant Nitrogen Oxides and Sulfur Dioxide Emission Reductions on Atmospheric Nitrogen Deposition " Journal of Air and Waste Management 60: 287-293.

Wang, F. e. A. (2010). "Particle number, particle mass and NOx emission factors at a highway and a urban street in Copenhagen." Atmospheric Chemistry and Physics 10: 2745-2764.

Weisel, C. P. (2002). "Assesing Exposure to Air Toxics Relative to Asthma." Environmental Health Perspectives 110(4): 527-537.

Zhao, Y., Chen, Zhongming (2010). "Application of Fourier Transform Infrared Spectroscopy in the study of atmospheric herterogeneous processes." Applied Spectroscopy 45(1): 63-91.

Zhou, Y., Ye Wu, Liu Yang, Lixin Fu, Kebin He, Shuxiao Wang (2010). "The impact of transportation control measures on emission reductions during the 2008 Olympic Games in Beijing, China." Atmospheric Environment 44: 285-293. 